\title{
The roles of transition metals in the physiology and pathogenesis of Streptococcus pneumoniae
}

\author{
Erin S. Honsa ${ }^{\dagger}$, Michael D. L. Johnson ${ }^{\dagger}$ and Jason W. Rosch * \\ Department of Infectious Diseases, St. Jude Children's Research Hospital, Memphis, TN, USA
}

Edited by:

Mathieu F. Cellier, Institut National de la Recherche Scientifique,

Canada

Reviewed by:

Zehava Eichenbaum, Georgia State

University, USA

James C. Paton, University of

Adelaide, Australia

*Correspondence:

Jason W. Rosch, Department of Infectious Diseasesm, St. Jude

Children's Research Hospital, Mail Stop 320, 262 Danny Thomas Place, Memphis, TN 38105-3678, USA e-mail: jason.rosch@stjude.org

t'These authors have contributed equally to this work.
For bacterial pathogens whose sole environmental reservoir is the human host, the acquisition of essential nutrients, particularly transition metals, is a critical aspect of survival due to tight sequestration and limitation strategies deployed to curtail pathogen outgrowth. As such, these bacteria have developed diverse, specialized acquisition mechanisms to obtain these metals from the niches of the body in which they reside. To oppose the spread of infection, the human host has evolved multiple mechanisms to counter bacterial invasion, including sequestering essential metals away from bacteria and exposing bacteria to lethal concentrations of metals. Hence, to maintain homeostasis within the host, pathogens must be able to acquire necessary metals from host proteins and to export such metals when concentrations become detrimental. Furthermore, this acquisition and efflux equilibrium must occur in a tissue-specific manner because the concentration of metals varies greatly within the various microenvironments of the human body. In this review, we examine the functional roles of the metal import and export systems of the Gram-positive pathogen Streptococcus pneumoniae in both signaling and pathogenesis.

Keywords: Streptococcus pneumoniae, pathogenesis, metal transport, virulence factors, infection

\section{METALS AND INFECTION}

Streptococcus pneumoniae can cause a variety of infections, including meningitis, otitis media, bacteremia, and pneumonia-the infection causing the most deaths worldwide from this pathogen (Wardlaw et al., 2006). During these various forms of bacterial infection, $S$. pneumoniae must acquire all necessary nutrients for survival and replication from within the host. Transition metals are an important subset of nutrients because they are required as cofactors and structural components of many proteins and play vital roles in metabolism and cellular defenses (Andreini et al., 2008). The bioavailability of metals in various host sites of pneumococcal colonization and infection vary significantly, which is reflected by the contribution to virulence of different pneumococcal metal import and export systems in these various host niches.

Although the efficient acquisition of metals is important, overaccumulation of intracellular metals can have deleterious effects on multiple cellular pathways, including antioxidant defense and central metabolic pathways. As such, bacteria have evolved highly efficient efflux mechanisms and precise regulatory systems to ensure appropriate modulation of intracellular metal accumulation. In addition to the concentration of a particular metal, the relative concentration of a particular metal in relation to that of other metals is a vital aspect of bacterial physiology because these metals can compete for intracellular binding sites within proteins (Dudev and Lim, 2008).

Baseline levels of metals vary greatly between various sites in the human body. As a reference, we have provided published concentrations of these metals in various body sites (McDevitt et al., 2011), as well as the pneumococcal transporters associated with these transition metals (Figure 1). In response to infection and inflammation, the bioavailability of metals can be rapidly altered, with the host sequestering nutrients from the bacterium to limit bacterial growth (Corbin et al., 2008; Weinberg, 2009; White et al., 2009). For example, the calprotectin protein chelates zinc and manganese during infection, rendering them unavailable to the pathogenic bacterium (Kehl-Fie and Skaar, 2010). In response to pneumococcal infection, the levels of metals in host tissues can vary dramatically. For example, zinc in the blood increases more than 10-fold during infection (McDevitt et al., 2011). Another example of the host modulating metal concentrations occurs within the phagolysosome of immune cells. Here, the innate immune cell actively pumps out necessary metals such as manganese and iron and pumps in toxic metals such as copper and zinc to eliminate the pathogen (Jabado et al., 2000; Forbes and Gros, 2003; White et al., 2009; Botella et al., 2011). This arms race for metals can determine whether or not an infection would be successful. In this review, we examine the role of the transition metals manganese, iron, copper, and zinc in S. pneumoniae physiology and pathogenesis.

\section{MANGANESE}

Although metals are toxic to bacteria, which require export systems for sustained viability, metal ion homeostasis must be maintained because metals are essential for bacterial viability and survival. For S. pneumoniae, one such metal that is critical for sustained colonization and invasive disease is manganese $(\mathrm{Mn})$. $\mathrm{Mn}^{2+}$ is found in various concentrations within the human host, depending on the body site, and is an essential cofactor for many pneumococcal proteins. In this section, we will discuss the specific 


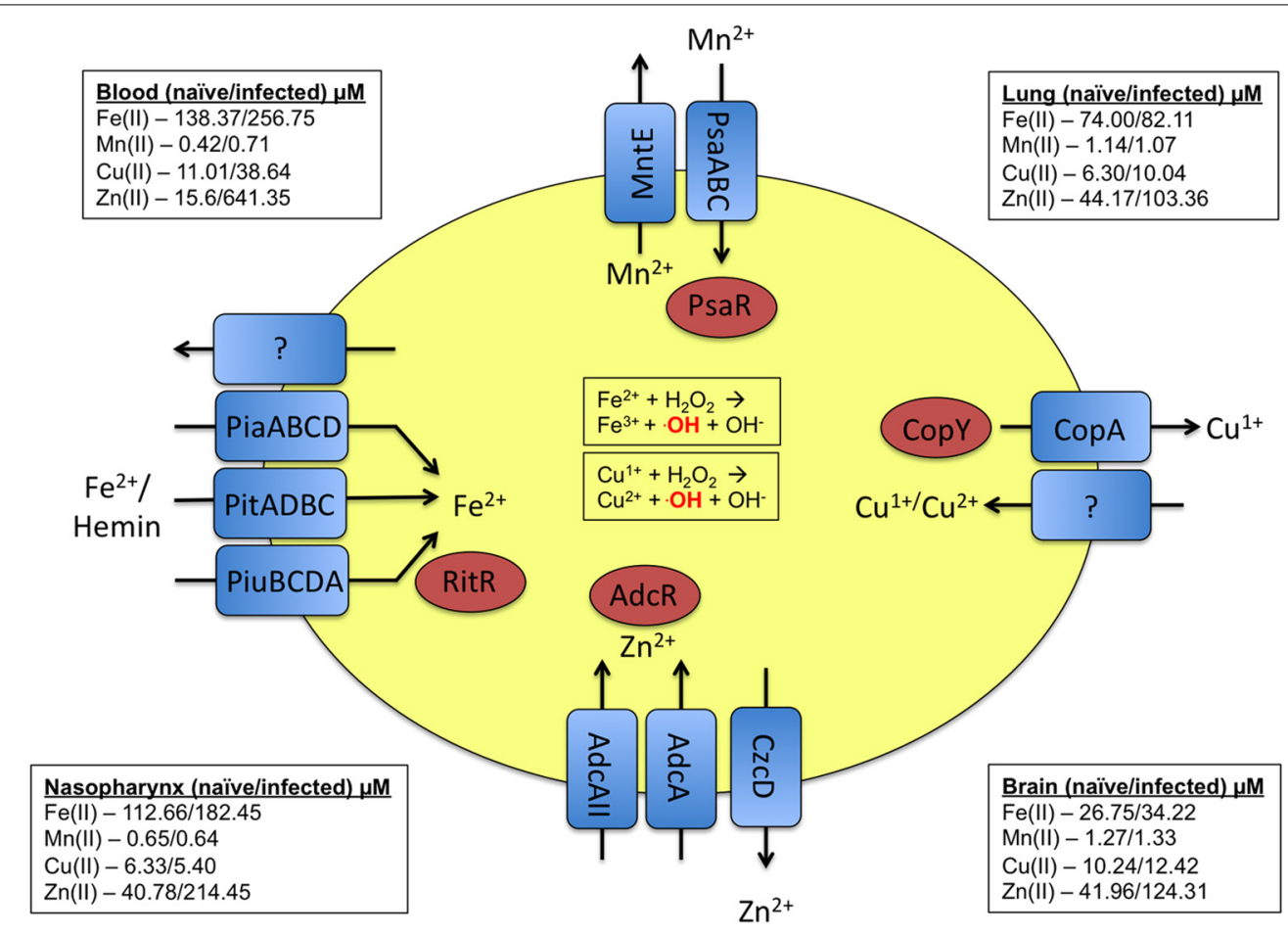

FIGURE 1 | Summary of the metal uptake and efflux systems of pneumococcus. Transporters and their respective substrates are indicated in blue. The regulators that respond to the respective metals are indicated in red. As a point of reference, the levels of the discussed metals at various host sites in both naive and infected animals are provided in the corners of the diagram (McDevitt et al., 2011). roles that this divalent metal plays in S. pneumoniae growth and virulence, as well as the antioxidant properties of $\mathrm{Mn}^{2+}$. Table 1 lists all $\mathrm{Mn}^{2+}$-related proteins and genes of S. pneumoniae that will be discussed.

\section{MANGANESE IMPORTER: PsaBCA}

The pneumococcal $\mathrm{Mn}^{2+}$-importer is the PsaBCA ATP-binding cassette $(\mathrm{ABC})$ transporter, which acquires and pumps $\mathrm{Mn}^{2+}$ ions from the extracellular environment (i.e., mammalian host) into the cytosol. PsaBCA belongs to the Cluster A-I substrate binding protein transporters, which can transport $\mathrm{Mn}^{2+}, \mathrm{Fe}^{2+}$, and $\mathrm{Zn}^{2+}$ (Figure 1). However, deletion of the transmembrane and ATP-binding components ( $\mathrm{PsaC}$ and $\mathrm{PsaB}$, respectively) results in an absolute requirement for $\mathrm{Mn}^{2+}$ in the growth medium (Novak et al., 1998; Johnston et al., 2006; Berntsson et al., 2010), suggesting that $\mathrm{Mn}^{2+}$ is the transporter's preferred substrate. Furthermore, cells lacking the PsaA component are deficient in growth in defined media lacking $\mathrm{Mn}^{2+}$ (Dintilhac et al., 1997; Novak et al., 1998).

The PsaA component was the first member of the Cluster A-I family substrate binding transportation proteins to be crystallized, with structures showing a $\mathrm{Zn}^{2+}$ ion within the metalcoordination site. However, free $\mathrm{Zn}^{2+}$ is unable to downregulate PsaBCA expression, suggesting that $\mathrm{Zn}^{2+}$ is not the natural ligand of PsaA (Kloosterman et al., 2008). Two published studies have shown that PsaA binds to $\mathrm{Zn}^{2+}$ with a higher affinity than it does to $\mathrm{Mn}^{2+}$ and that PsaA- $\mathrm{Zn}^{2+}$ binding is responsible for an $\sim 40 \%$ reduction in $\mathrm{Mn}^{2+}$ accumulation in the cytosol (Jacobsen et al., 2011; McDevitt et al., 2011). $\mathrm{Zn}^{2+}$ binding to PsaA, therefore, partially inhibits $\mathrm{Mn}^{2+}$ binding and subsequent import. This phenomenon of inhibiting nutrient acquisition by the bacterium may partially explain why extracellular $\mathrm{Zn}^{2+}$ is toxic to S. pneumoniae, as will be discussed later.

PsaA's mechanism of $\mathrm{Mn}^{2+}$ import has recently been determined through a series of elegant structural and biochemical experiments (Counago et al., 2013). The metal-coordinating residues of PsaA were shown to interact with both $\mathrm{Mn}^{2+}$ and $\mathrm{Zn}^{2+}$, similar to previously published observations, with the subsequent release and intracellular import of $\mathrm{Mn}^{2+}$ found to be facilitated by the sub-optimal coordination of $\mathrm{Mn}^{2+}$ in the metalbinding site. In contrast, optimal coordination of zinc resulted in the locking of the conformation of PsaA in a manner whereby the zinc ion was not released. This situation highlights the importance of ligand specificity and biological function, as many such import machineries must discriminate between metals of varying reactivity and abundance in the host.

\section{MANGANESE-DEPENDENT GENE REGULATION}

The psabCA operon repressor PsaR negatively regulates the Psa import machinery. The recently elucidated crystal structure of the S. pneumoniae PsaR forms a stable homodimer and contains two metal-binding sites (Lisher et al., 2013). Site one coordinates $\mathrm{Zn}^{2+}$ with a $K_{D} \geq 10^{13} \mathrm{M}^{-1}$. Site two mediates metal selectivity and DNA activation of PsaR. Although $\mathrm{Zn}^{2+}$ bound to this site with a higher affinity than did $\mathrm{Mn}^{2+}, \mathrm{Mn}^{2+}$ was essential for the activation of DNA binding by PsaR. This requirement 
Table 1 | Summary of Streptococcus pneumoniae genes and their products involved in transition metal import/export, and metal-dependent proteins.

\begin{tabular}{|c|c|c|c|c|c|}
\hline Operon & Gene & SP number (TIGR4) & Protein product & Role in virulence (mutant) & Reference/s \\
\hline \multirow{3}{*}{$\begin{array}{l}\text { psaABC } \\
\text { (Manganese } \\
\text { import) }\end{array}$} & $p s a B$ & SP_1648 & $\begin{array}{l}\text { Manganese ABC transporter } \\
\text { ATP-binding protein }\end{array}$ & $\begin{array}{l}\text { Absolute requirement for } \mathrm{Mn}^{2+} \text { in } \\
\text { growth media. }\end{array}$ & $\begin{array}{l}\text { Berry and Paton, 1996; } \\
\text { Johnston et al., } 2006\end{array}$ \\
\hline & psaC & SP_1649 & $\begin{array}{l}\text { Manganese } A B C \text { transporter } \\
\text { permease }\end{array}$ & $\begin{array}{l}\text { Absolute requirement for } \mathrm{Mn}^{2+} \text { in } \\
\text { growth media. }\end{array}$ & $\begin{array}{l}\text { Berry and Paton, 1996; } \\
\text { Johnston et al., } 2006\end{array}$ \\
\hline & sodA & SP_0766 & $\begin{array}{l}\text { Manganese-dependent } \\
\text { superoxide dismutase }\end{array}$ & $\begin{array}{l}\text { Dispensible for systemic } \\
\text { infection. Essential for initial lung } \\
\text { infection and invasion into the } \\
\text { bloodstream. }\end{array}$ & Yesilkaya et al., 2000 \\
\hline \multirow[t]{4}{*}{$\begin{array}{l}\text { piuBCDA (Iron } \\
\text { import) }\end{array}$} & piuA & SP_1872 & Iron lipoprotein receptor & $\begin{array}{l}\text { No effect on pneumonia or } \\
\text { systemic modes of infection. } \\
\text { Double mutant with the pia } \\
\text { system demonstrated delayed } \\
\text { time to death in systemic } \\
\text { infection. }\end{array}$ & $\begin{array}{l}\text { Brown et al., 2001a, } \\
2002\end{array}$ \\
\hline & piuB & SP_1869 & Transmembrane permease & & \\
\hline & piuc & SP_1870 & Transmembrane permease & & \\
\hline & piuD & SP_1871 & ATPase component & & \\
\hline \multirow{2}{*}{$\begin{array}{l}\text { piaABCD (Iron } \\
\text { import) }\end{array}$} & piaC & SP_1034 & Transmembrane permease & & \\
\hline & piaD & SP_1035 & ATPase component & & \\
\hline \multirow[t]{5}{*}{$\begin{array}{l}\text { pitADBC (Iron } \\
\text { import) }\end{array}$} & pitA & SP_0240 & Iron lipoprotein receptor & $\begin{array}{l}\text { Deletion of operon had no effect } \\
\text { on pneumonia model of infection. } \\
\text { Slight role in systemic infection. } \\
\text { Additive affect when knocked out } \\
\text { with piu and pia systems. }\end{array}$ & Brown et al., 2002 \\
\hline & pitB & SP_0242 & Transmembrane permease & & \\
\hline & pitC & SP0243 & Transmembrane permease & & \\
\hline & pitD & SP_0241 & ATPase component & & \\
\hline & ritR & SP_0376 & Repressor of iron transport & Required for murine pneumonia. & $\begin{array}{l}\text { Throup et al., 2000; } \\
\text { Ulijasz et al., } 2004\end{array}$ \\
\hline \multirow{2}{*}{$\begin{array}{l}\text { copY/cupA/copA } \\
\text { (Copper export) }\end{array}$} & $\operatorname{cop} Y$ & SP_0727 & cop operon regulator & N/A & Shafeeq et al., 2011b \\
\hline & cupA & SP_0728 & $\begin{array}{l}\text { Copper transport protein and } \\
\text { potential cupredoxin }\end{array}$ & $\begin{array}{l}\text { Slightly More Sensitive Than Wild } \\
\text { Type to copper in growth media }\end{array}$ & Shafeeq et al., 2011b \\
\hline
\end{tabular}


Table 1 | Continued

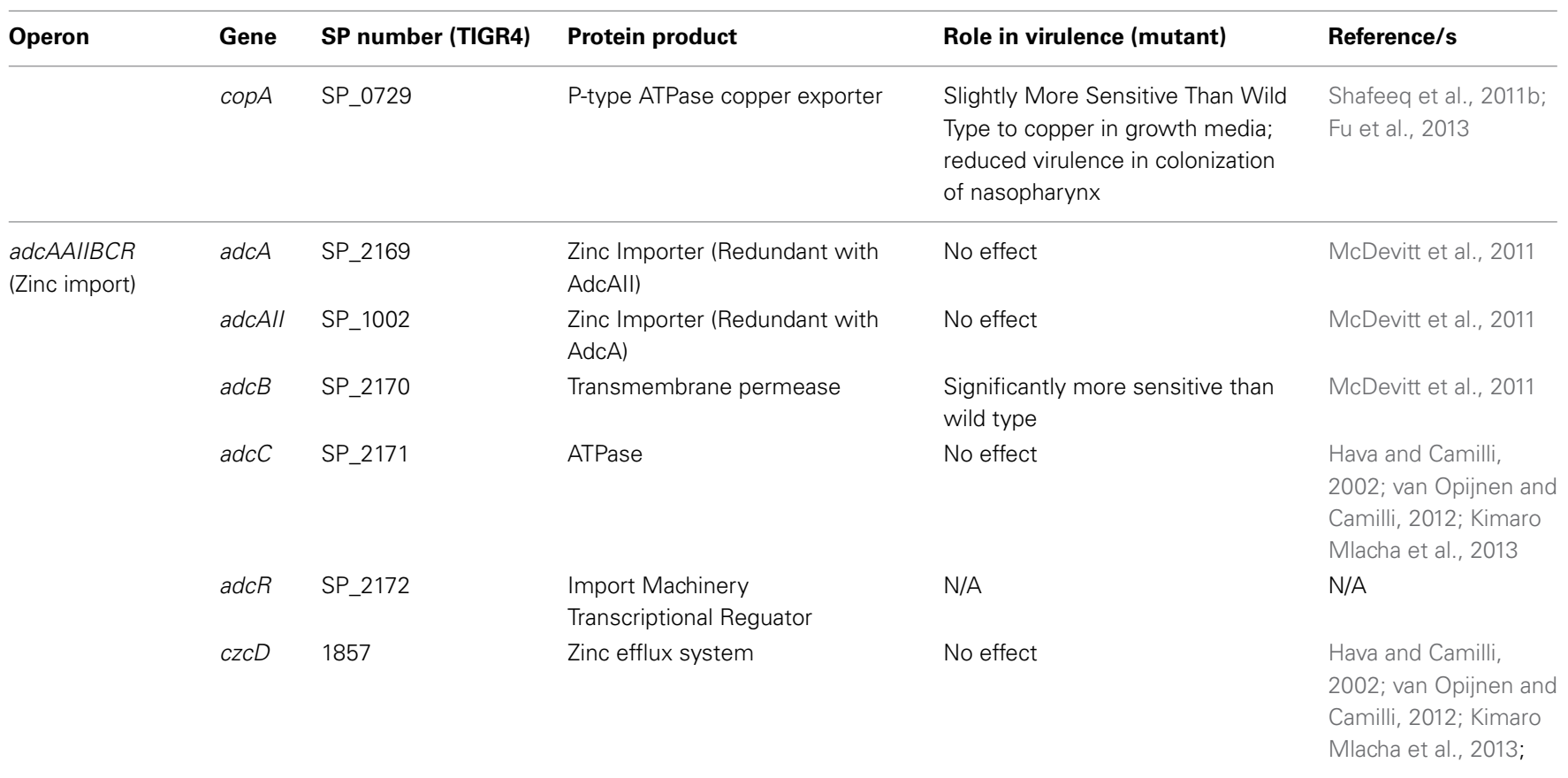

N/A, not available.

for $\mathrm{Mn}^{2+}$ is due to the higher allosteric coupling free energy released when $\mathrm{Mn}^{2+}$ binds to site two than when $\mathrm{Zn}^{2+}$ binds. Altogether, this study elucidated the first PsaR crystal structure and showed that PsaR requires $\mathrm{Mn}^{2+}$ to be bound within site two for DNA binding activity, and most likely psaBCA gene repression.

$\mathrm{Mn}^{2+}$ also plays an important role in the ability of the pneumococcus to regulate its response to stressors (Balogun et al., 2010). Global transcriptomic and proteomic analyses of WT and $\triangle p s a A$ pneumococci, grown under high- or low- $\mathrm{Mn}^{2+}$, revealed the overall effect of $\mathrm{Mn}^{2+}$ on various biological processes of the pneumococcus. In the absence of supplemental $\mathrm{Mn}^{2+}$, the psaBCA gene expression was increased, consistent with the Mndependent binding of PsaR (repressor) to the promoter of the $p s a$ operon, when excess $\mathrm{Mn} 2+$ was present in the bacterial cytosol (Johnston et al., 2006). Additional genes were also controlled by the PsaR regulator, including the virulence factors prtA ( $s p 0641$ ) and $p c p A$ (sp2136), which encode a cell wall-associated serine protease and CbpA, respectively (Hoskins et al., 2001).

$\mathrm{Mn}^{2+}$ has also been implicated in the development of natural competence in the pneumococcus. In fact, the $\Delta p s a A$ strain absolutely requires $\mathrm{Mn}^{2+}$ supplementation in the growth media for competence and transformation (Dintilhac et al., 1997). Transcriptome analysis results provided the first real evidence that PsaA was needed to induce competence. Because PsaA is also required for $\mathrm{Mn}^{2+}$ import, this finding suggested that a certain level of $\mathrm{Mn}^{2+}$ must be present in the cytosol to trigger competence. Indeed, the competence transcriptional regulator $\operatorname{comX1}$, the competence operon, and the competence-stimulating peptide were all downregulated in strains lacking psaA.

\section{THE ROLE OF MANGANESE IN PROTECTION AGAINST OXIDATIVE STRESS}

When the expression of the ligand-binding lipoprotein $p s a A$ was knocked out, the resultant $\triangle p s a A$ pneumococcus was hypersensitive to oxidative stress and had lowered ability to neutralize the reactive oxygen species (ROS) superoxide anions (Tseng et al., 2002). For S. pneumoniae, ROS accumulation is a particularly volatile situation because this bacterium does not express a catalase, an enzyme essential for breaking down and neutralizing $\mathrm{H}_{2} \mathrm{O}_{2}$ (Hoskins et al., 2001). Furthermore, during the normal function of the pyruvate oxidase $\mathrm{SpxB}$, which is required for the decarboxylation of pyruvate to acetyl phosphate and $\mathrm{CO}_{2}$, high levels of $\mathrm{H}_{2} \mathrm{O}_{2}$ are produced as a byproduct (Spellerberg et al., 1996). In fact, when $\mathrm{SpxB}$ is absent from a mutant strain of pneumococcus, the relative levels of cytosolic $\mathrm{H}_{2} \mathrm{O}_{2}$ drop $99 \%$, suggesting that $\mathrm{SpxB}$ is the major $\mathrm{H}_{2} \mathrm{O}_{2}$-producing protein. Therefore, the pneumococcus and many other bacteria have evolved systems to break down ROS molecules to prevent oxidative stress. Because the $\triangle p s a A$ mutant is unable to acquire $\mathrm{Mn}^{2+}$, it is proposed that the loss of the antioxidant property of $\mathrm{Mn}^{2+}$ is responsible of the accumulation of ROS, resulting in oxidative damage and cell death (Spellerberg et al., 1996). Although $\mathrm{Mn}^{2+}$ is a cofactor for many proteins, the Mn-bicarbonate complex can also reduce ROS molecules directly, without the need for enzymes (Daly et al., 2004). However, this Mn-dependent ROS neutralization activity has not yet been found in the pneumococcus.

The superoxide anion $\left(\mathrm{O}_{2}^{-}\right)$is a major source of oxidative stress within the pneumococcus. Sod metalloenzymes neutralize superoxide anions by converting them to molecular water and $\mathrm{H}_{2} \mathrm{O}_{2}$, and are a major cellular defense against oxidative stress 
(McCord and Fridovich, 1969; Hassan, 1989). Although the production of $\mathrm{H}_{2} \mathrm{O}_{2}$ itself may be deleterious to the pneumococcus, previous results suggest that the $\mathrm{Mn}$-dependent superoxide dismutase SodA is responsible for only $1 \%$ of pneumococcal $\mathrm{H}_{2} \mathrm{O}_{2}$ production. Furthermore, as we have discussed, $\mathrm{SpxB}$ was responsible for the remaining 99\% (Spellerberg et al., 1996). Therefore, although the mechanism of $\mathrm{H}_{2} \mathrm{O}_{2}$ neutralization by the pneumococcus remains unknown, the role of SodA is highly critical for the survival and virulence of the pneumococcus when grown in a high oxidative stress environment.

Yesilkaya et al. reported the first detailed information on the pneumococcal Mn-dependent SodA, its role in protecting against oxidative stress, and its possible role in virulence (Yesilkaya et al., 2000). They showed that the pneumococcus produces two Sod proteins: a Mn-dependent Sod (SodA) and an iron-dependent Sod that is inhibited by $\mathrm{H}_{2} \mathrm{O}_{2}$. The pneumococcal genome clearly contained $\operatorname{sodA}$, but no other discernible superoxide dismutase homologs have been identified to date. It should be noted that the presence of an iron-dependent SodA has not been addressed since the original study. Deleting sodA impairs pneumococcal growth under aerobic conditions, most likely due to the loss of the Mn-driven neutralization of $\mathrm{O}_{2}^{-}$produced during growth in a high molecular oxygen environment (Yesilkaya et al., 2000). Furthermore, the mutation is lethal under anaerobic conditions. The authors suggest that this result may be due to the loss of superoxide scavenging function during anaerobic growth in this highly limiting growth medium and that the cells are highly susceptible to death by oxidative stress without the Mndependent SodA.

\section{MANGANESE EFFLUX}

As with all biological systems, pneumococci must achieve equilibrium between the amount of nutrient acquired and the amount of nutrient required. In the case of $\mathrm{Mn}^{2+}$, which serves a positive role in the growth and virulence of the pneumococcus, there may be negative side effects to its accumulation within the cytosol if levels exceed those needed. To help control this tight regulation, the pneumococcus encodes a $\mathrm{Mn}^{2+}$. efflux protein MntE, which selectively removes excess $\mathrm{Mn}^{2+}$ from the cytosol to maintain metal homeostasis (Figure 1) (Rosch et al., 2009). MntE was originally predicted to be a CDF inorganic cation transporter, however, its substrate was unknown (Tettelin et al., 2001). Subsequent analysis of a $\Delta m n t E$ mutant showed its enhanced sensitivity to high levels of $\mathrm{Mn}^{2+}$ in the growth medium, attributed to the inability of the mutant to export internal $\mathrm{Mn}^{2+}$ ions (Rosch et al., 2009). Also, the levels of intracellular $\mathrm{Mn}^{2+}$ in the mutant were significantly higher than those of the parental strain. These data indicate that MntE functions as a manganese efflux transporter in the pneumococcus.

\section{MANGANESE HOMEOSTASIS AND VIRULENCE}

Based on the importance of manganese to the pneumococcus, it was not unexpected that the $\triangle p s a A$ mutant was highly attenuated for multiple modes of pneumococcal infection, including otitis media, respiratory infection, and systemic invasion (Berry and Paton, 1996; Marra et al., 2002). One of the critical steps in pneumococcal pathogenesis is the initial adherence to and invasion of host cells, and a $\triangle p s a A$ strain of pneumococcus has decreased adherence to mammalian cells (Berry and Paton, 1996). Although it was originally hypothesized that PsaA was a surface-exposed adhesin, subsequent studies showed that PsaA plays a predominantly regulatory role in adherence, attributed to the important cellular role of the Mn-dependent repressor PsaR. Furthermore, perturbing manganese import affected the levels of the structural adhesin CbpA, an important virulence determinant for the pneumococcus, on the bacterial surface (Novak et al., 1998). It was, therefore, proposed that Mn-import by PsaBCA and the Mn-homeostasis role of PsaR are ultimately responsible for patterns of CbpA expression and pneumococcal adherence (Paton, 1998). Subsequent work showed that although PsaR is responsible for the negative expression of the Mn-transporter PsaBCA and several other surface proteins, PsaR inactivation does not alter pneumococcal adherence to cultured nasopharyngeal cells (Johnston et al., 2006). Also, though PsaR-mediated repression is essential for the pneumococcus to establish a systemic infection, Mn-dependent signaling through PsaR is not required for nasopharyngeal colonization (Johnston et al., 2006). This discrepancy may be due to the differences between the Mn levels of the lungs and those of the nasopharynx, which are shown in Figure 1. Regardless, these findings highlight the importance of $\mathrm{Mn}^{2+}$ acquisition during pneumococcal infection.

The results of initial studies of intranasal models of infection suggested that SodA may also have a role in the initial colonization of the lung tissue and subsequent invasion into the bloodstream (Yesilkaya et al., 2000). To confirm this hypothesis, animals were intravenously infected with WT and $\Delta$ sodA pneumococcal strains. No differences in median survival times were observed, suggesting that SodA is dispensable during a systemic pneumococcal infection (Yesilkaya et al., 2000). These findings may suggest that the microenvironment of the lungs, being rich in molecular oxygen, is the site of maximal SodA activity, protecting against the high oxidative stress levels. The delay in infection as the bacteria traverse the oxygen-rich alveoli into the more micro-aerophilic bloodstream suggests the ability of Mn-SodA to neutralize cytosolic oxidative stress is a determinant of pneumococcal pathogenesis and that is dispensable once the bacteria reach the bloodstream. This finding highlights the importance of understanding the niche-specific contribution of virulence genes to pathogenesis.

$\mathrm{Mn}^{2+}$ accumulation in the cytosol increases S. pneumoniae resistance to oxidative stress (Rosch et al., 2009). This finding was expected because $\mathrm{Mn}^{2+}$ is an antioxidant and is the cofactor for SodA, which eliminates ROS from the cytosol. The high accumulation of $\mathrm{Mn}^{2+}$ in the $m n t E$ mutant can, however, be detrimental: increased internal concentrations of $\mathrm{Mn}^{2+}$ dysregulate the transcriptional profile of the pneumococcus, altering multiple cellular pathways (Rosch et al., 2009). Although the results of in vitro studies demonstrated that the $\triangle m n t E$ pneumococcus is viable even under higher levels of oxidative stress, the results of in vivo pathogenicity studies indicate a fitness tradeoff for these benefits. The $\Delta m n t E$ mutant has a significantly reduced ability to colonize the nasopharynx and establish systemic infection (Rosch et al., 2009). Therefore, communication at a transcriptional level 
in response to internal and external $\mathrm{Mn}^{2+}$ levels is of critical importance during disease progression.

\section{TARGETING MANGANESE HOMEOSTASIS FOR VACCINES}

Because of both its surface location and important roles in virulence, PsaA has attracted considerable interest as a potential vaccine antigen for the pneumococcus. The current polyvalent pneumococcal vaccine is based on the polysaccharide capsule, of which there are more than 90 serotypes (Robbins and Schneerson, 1983; Robbins et al., 1983). Since the vaccine only protects against 23 of the most common serotypes, non-vaccine-type pneumococci have emerged that are capable of causing pneumonia and invasive diseases. Therefore, one major goal in the pneumococcal field is to develop a protein-based vaccine that targets one or more surface-exposed pneumococcal proteins. Candidate proteins must be present in all serotypes and elicit a strong serotypeindependent immune response. Immunization of mice with PsaA conferred protection against invasive pneumococcal disease in a serotype-independent manner (Talkington et al., 1996). Inclusion of PsaA in multicomponent protein-based vaccines has also been efficacious for protection against both colonization and invasive disease (Briles et al., 2000; Ogunniyi et al., 2000). Hence, inclusion of such surface-exposed, metal-acquisition proteins may play an important role in the development of the next generation of pneumococcal vaccines.

\section{IRON}

In the 1990s and early 2000s, substantial information was available about how Gram-negative pathogens acquired iron from their hosts (Crosa et al., 2004). Two main systems had been discovered: (1) small molecular siderophores that are synthesized and secreted by the bacteria to sequester free iron atoms or iron from host proteins such as transferrin; and (2) bacteria expressed surface proteins that bound hemin and imported the porphyrin into the cytosol for iron utilization. However, it remained unclear how Gram-positive organisms acquired iron through the thick cell wall and a single membrane.

\section{HOST SOURCES OF IRON USED BY PNEUMOCOCCI}

In 1993, Tai and others began to uncover how the pneumococcus acquires iron from its host during systemic bacteremia (Tai et al., 1993). Free iron levels in the blood are $\sim 10^{-18} \mathrm{M}^{-1}$ in the mammalian host, with most iron sequestered within the tetrapyrrole ring of heme, which is bound to hemoglobin $(\mathrm{Hb})$ in erythrocytes (De Domenico et al., 2008; Heinemann et al., 2008). Initial analysis focused on determining whether pneumococcal culture supernatants contain siderophores as do those from multiple Gram-negative and Gram-positive pathogens, including Escherichia coli, Yersinia pestis, Haemophilus influenzae, Bacillus anthracis, and Staphylococcus aureus (Crosa et al., 2004; Honsa and Maresso, 2011; Haley and Skaar, 2012). However, no siderophores were present in the supernatants of pneumococcal cultures grown in low-iron media, suggesting that the pneumococcus does not produce iron-scavenging siderophores for iron acquisition (Tai et al., 1993).

The possibility existed that the pneumococcus could acquire iron via hemin sources or other iron-atom acquisition systems such as transferrin-iron capture, as seen in Neisseria meningitidis and similar pathogens (Gray-Owen and Schryvers, 1996; Pintor et al., 1998). This hypothesis was tested by using pneumococci grown in EDTA-treated media whereby growth was inhibited due to low iron levels. Supplementation with iron-loaded (holo) transferrin or lactoferrin did not restore growth, suggesting that while the pneumococcus is a mucosal pathogen, it does not use these two host iron sources (Tai et al., 1993). However, when cells were grown in hemin or $\mathrm{Hb}$, bacterial growth recovered to WT levels, providing the first evidence that the pneumococcus may exploit host hemin stores for iron during growth in the bloodstream. Furthermore, this was the first evidence that any Gram-positive pathogen could use hemin as an iron source.

Tai et al. continued to study possible hemin-binding and acquisition functions of the pneumococcus (Tai et al., 1997). They used a non-encapsulated strain of pneumococcus to detect heme-binding activity by cell wall proteins. As increasing concentrations of hemin were incubated with live pneumococci, the absorbance at $405 \mathrm{~nm}$, a well-defined method to detect hemin in a sample (Berry and Trumpower, 1987), increased by nearly a $1: 1$ ratio with $\sim 70 \%$ of hemin bound to the pneumococcal surface. Furthermore, pretreating cells at $75^{\circ} \mathrm{C}$ did not inhibit hemin binding, suggesting that hemin binding does not require metabolically active cells. Although this heating may destroy proteins that could be responsible for hemin binding, treating pneumococci with proteinase $\mathrm{K}$ also did not inhibit hemin association with the bacterial cell surface. In an attempt to identify the polypeptides responsible for hemin binding, batch affinity chromatography was performed, with hemin-coated agarose beads used to capture potential heminbinding surface proteins (Tai et al., 1997). Several protein bands were seen, with the dominant species being $43 \mathrm{kDa}$, and adding free hemin to the cell lysate before column filtration eliminated the elution of the $43-\mathrm{kDa}$ band. This $43-\mathrm{kDa}$ protein was found in all pneumococcal serotypes tested and was predicted to be cell surface-exposed via fractionation results; hence, it was the most-promising candidate for a hemin-binding factor at the pneumococcal surface. Recently, researchers preliminarily identified two pneumococcal membrane proteins that bound hemin and $\mathrm{Hb}$ and were essential for viability (Romero-Espejel et al., 2013). As such these candidates show promise for the future understanding of how the pneumococcus acquires these complexes.

Elucidation of the details of iron transport can sometimes be confounded by the biochemistry of hemin and hemoglobin. One such difficulty can be non-specific binding of hemin to the bacterial cell surface, which can occur due to the hydrophobic nature of hemin. Another potential issue is that $\mathrm{Hb}$ can begin to dissociate during prolonged incubation: that is, heme will be oxidized to produce hemin and will dissociate from $\mathrm{Hb}$ subunits (Hargrove et al., 1997). Also, in some reported instances, hemin-binding proteins transiently bind porphyrin, and this event can be followed by a rapid dissociation of apo-hemin from the protein (Tsuruga and Shikama, 1997). As such, care must be taken to address these factors when investigating hemin and $\mathrm{Hb}$ utilization. 


\section{THE IRON IMPORT MACHINERY OF PNEUMOCOCCUS}

The ability to scavenge free iron atoms and the protein complexes responsible for this activity had not been discovered in the pneumococcus until two possible iron-import machineries were identified (Brown et al., 2001a). In this study, it was hypothesized that possible virulence determinants, which include iron importers, could be found in pathogenicity-associated islands. A previously performed signature-tagged mutagenesis screen used insertion-duplication mutants that were analyzed for their ability to survive and replicate in murine models of pneumonia and bacteremia. One gene, $s m t A$, was attenuated for virulence, and was annotated as a $\mathrm{Fe}^{3+} /$-dicitrate $\mathrm{ABC}$ transporter (Figure 1) (Lau et al., 2001). This gene was predicted to encode a transmembrane permease and was initially termed the pit1BCDA operon (pneumococcal iron transporter 1, now referred to as piuBCDA) (Figure 1) (Brown et al., 2001a). A second locus also discovered in this study was termed pit $2 A B C D$ (now referred to as piaABCD). Recently, PiaA was crystallized, revealing the ability of this membrane protein to bind ferrichrome, a hydroxamate siderophore (Cheng et al., 2013). While previous data determined that the pneumococcus does not produce siderophores, this new PiaA data may suggest that $S$. pneumoniae is capable of stealing holo-siderophores produced by other bacteria in the human host. This could possibly act as an iron source, and has been previously reported to be an iron-acquistion mechanism in other pathogenic bacteria (Hibbing et al., 2010).

For both the piu and pia loci, a single operon encoded a putative lipoprotein receptor, a putative ATPase, and two transmembrane permease proteins. All mutants had impaired growth abilities in cation-free media, with the double pia/piu mutant having the largest defect. Growth defects were reversed by the addition of $\mathrm{FeCl}_{3}$ and $\mathrm{FeCl}_{2}$ but not by that of ferritin or lactoferrin. Also, $\mathrm{Hb}$ partially restored the growth of the individual mutants but not that of the double mutant. This partial rescue of growth in the presence of $\mathrm{Hb}$ may be due to the ability of $\mathrm{Hb}$ or hemin to be imported through the Piu/Pia transporters. Of note is that during the growth experiments, hemin may also be released from $\mathrm{Hb}$ via spontaneous dissociation, and the oxidized iron in hemin could be dissociated under these conditions (Hargrove et al., 1997; Tsuruga and Shikama, 1997). Therefore, the Piu/Pia transporters could target this fresh heme-iron pool for import.

To corroborate the finding that one or both iron transporters have a role in iron import, the iron-dependent antibiotic streptonigrin was used to determine bacterial sensitivity (Brown et al., 2001a). This bacteriocidal antibiotic requires free iron in the cytosol of bacteria; therefore, bacteria are resistant to this drug when their iron import systems are disrupted. The individual mutants both showed $\sim 10$-fold less sensitivity to streptonigrin than did the WT strain, suggesting that the mutants had less iron accumulate within the cytosol of the single/double mutants. The double mutant was even more resistant to the iron-dependent killing via streptonigrin. These data indirectly show that the loss of one or both iron import systems reduces iron import. This study also demonstrated direct iron uptake into the cytosol and indicated that significantly lower levels of iron accumulate within the cytosol (Brown et al., 2001a). These data clearly indicate the role of both the Piu and Pia systems in mediating iron uptake by the pneumococcus.

A third operon was discovered to contain genes encoding proteins similar to the already characterized iron import systems (Hoskins et al., 2001; Brown et al., 2002). The new putative iron import system was named pitADBC (Figure 1). The pitA gene encoded a lipoprotein iron receptor; $p i t D$ encoded an ATPase, and $p i t B$ and $p i t C$ encoded transmembrane permease proteins. At an amino acid level, PitA has more homology to Streptococcus equi and Streptococcus pyogenes PitA-homologs than to the pneumococcal PiuA and PiaA. The single pitA, piuB, and piaA mutants have WT-like growth characteristics in several growth media (Brown et al., 2002). However, growth is delayed in chelated media, and exogenous $\mathrm{FeCl}_{3}$ partially restores this growth defect. In contrast, adding $\Delta$ pitA to the double piu/pia mutant further reduces growth in all media tested, and this growth was partially restored in cation-free media by adding $\mathrm{FeCl}_{3}$ (Brown et al., 2002). These data indicate that some degree of specificity exists among these partially redundant systems.

\section{REGULATION OF IRON TRANSPORT}

Although iron import systems are needed for the pneumococcus to acquire iron, this acquisition process must be tightly regulated at a transcriptional level for optimal detection of and response to the environmental stimuli encountered during infection. Because the pneumococcus inhabits multiple body sites, it is extremely important to detect extracellular and intracellular nutrient levels. Two-component systems (TCSs) can regulate such events, and studies to determine the role of TCSs within the pneumococcus revealed the existence of 13 such systems and one orphan response regulator, RitR (Lange et al., 1999; Throup et al., 2000; Tettelin et al., 2001). The results of studies initiated by Throup et al. and expanded upon by Ulijasz et al. show that the RitR (repressor of iron transport) regulator is required during murine lung infection (Throup et al., 2000; Ulijasz et al., 2004). Additional data show that this regulator may repress iron acquisition genes in high-iron environments.

Global transcriptional profiling efforts to determine the genes under control of RitR identified 54 genes, with 17 repressed and 37 activated in the pneumococcal WT R800 strain (Ulijasz et al., 2004). Notable changes in gene expression for this review were the following: (i) piuB and piuA (but not piuC or piuD), which showed the highest degree of differential gene expression and were repressed in WT R800; (ii) increased expression of Dpr homologs, which are iron-storage peroxide-resistance proteins, and the iron-binding alcohol dehydrogenase AdhE, both of which are proposed to protect bacterial cells against $\mathrm{H}_{2} \mathrm{O}_{2}$ damage (Echave et al., 2003; Pulliainen et al., 2003); (iii) HemH, which is responsible for the final step in heme synthesis (Panek and O'Brian, 2002); and (iv) MutY, an iron-sulfur protein that is required for A/G DNA mismatch repair, which occurs during oxidative stress (Michaels et al., 1992; Grollman and Moriya, 1993; Samrakandi and Pasta, 2000). Therefore, it seems that RitR is important for the controlled expression or repression of genes involved in oxidative stress response and protection.

To further analyze the effect that RitR has on the iron-uptake system Piu, streptonigrin sensitivity was measured to indirectly 
detect iron uptake (Ulijasz et al., 2004). When grown in irondeplete media with no iron supplementation, the WT R800 and $\Delta$ ritR strains grew to similar levels and were resistant to streptonigrin. However, when $\mathrm{Fe}^{2+}$ or hemin was added to the media, only the $\Delta r i t R$ mutant had increased susceptibility to streptonigrin killing (Ulijasz et al., 2004). These findings suggest that when RitR is absent, iron uptake is dysregulated and the metal hyperaccumulates in the cytosol. However, adding $\mathrm{Fe}^{3+}$ and $\mathrm{Hb}$ did not increase the susceptibility of either strain to streptonigrin, suggesting that the pneumococcus cannot use these iron sources under these conditions. These $\mathrm{Hb}$ results are in contrast to those previously discussed in this review (Tai et al., 1993). Additionally, the $\Delta$ rit $R$ strain is hyper-susceptible to $\mathrm{H}_{2} \mathrm{O}_{2}$ damage but not to the superoxide anion. The fact that RitR did not alter the expression of SodA is most likely responsible for maintenance of the resistance to oxidative stress caused by the superoxide anion. However, without a catalase, the pneumococcus would become increasingly susceptible to $\mathrm{H}_{2} \mathrm{O}_{2}$ damage, which would be further amplified by the higher intracellular $\mathrm{Fe}^{2+}$ concentrations that are present when RitR is absent.

Because RitR is a regulator of gene transcription that may be affected by differing $\mathrm{Mn}$ and Fe levels, Ong et al. analyzed gene expression of WT and $\Delta$ ritR strains grown in media with differing Fe:Mn ratios (Ong et al., 2013). The WT strain expressed two-fold more ritR in high-Fe media than in high-Mn media. This is consistent with reports that iron upregulates ritR (Ulijasz et al., 2004). The expression of $\operatorname{spxB}$, which generates $\mathrm{H}_{2} \mathrm{O}_{2}$, was higher in the ritR mutant when grown in high-Fe media than when grown in high-Mn media. This finding supports the detection of increased $\mathrm{H}_{2} \mathrm{O}_{2}$ and oxidative stress in the mutant grown in high-Fe media (Ong et al., 2013). Also, because high Fe itself can produce oxidative stress, the researchers analyzed whether levels of NADPH, which can detoxify ROS, are changed in high-Fe environments. Additionally, gnd, which is involved in pneumococcal NADPH generation and is directly upstream of ritR, is expressed at a higher level in WT and ritR mutant cells grown in high-Fe media than it is in those grown in high-Mn media (Lanie et al., 2007; Ong et al., 2013). This expression pattern is further enhanced in the ritR mutant. Compared to the WT and ritR-complemented strains, the ritR mutant also expresses elevated levels of $z w f$, another gene essential for NADPH generation, when grown in high-Mn media. Additionally, the WT and complemented strains express 12 -fold higher levels of the psaA gene in high-Fe media than in high-Mn media. However, the ritR mutant did not have increased $p s a A$ gene expression, suggesting that RitR may have a role in the expression of psaA.

Iron may also serve as a signal for a number of pneumococcal processes. Proteomic analysis of pneumococci cultured under iron-limiting conditions revealed altered expression of PsaA and numerous proteins involved in cellular stress responses and biofilm formation (Nanduri et al., 2008). The role of iron in biofilm formation has also been directly demonstrated, as supplementation of $\mathrm{Fe}^{3+}$ enhanced biofilm formation, and iron chelation severely impaired formation of these structures (Trappetti et al., 2011). The central regulator in the case of iron-dependent biofilm formation appears to be LuxS, which also controls expression of the iron importer PiuA (Trappetti et al., 2011). LuxS has been implicated in numerous cellular processes and is central for coordinating the formation of biofilms both on inert surfaces and on human respiratory cells (Vidal et al., 2011, 2013). These findings underscore the importance of iron in the regulation of diverse cellular processes in the pneumococcus.

\section{ROLE OF IRON TRANSPORTERS IN PNEUMOCOCCAL PATHOGENESIS}

To determine the roles of Piu and Pia iron transporters in virulence, both pneumonia and a systemic infection were studied in murine models (Brown et al., 2001a). No differences were seen in survival between WT and individual-mutant strains. However, all mice infected with the double mutant survived the pneumonia infection. In contrast, the double mutant still caused $90 \%$ mortality during systemic infection, although the time-to-death was significantly delayed. Mixed infections were used to determine a competitive index between the WT strain and each mutant strain to better understand the roles of each iron import system in virulence. Here, the pia deletion was more attenuated in both the pneumonia and systemic infectious routes, suggesting that this iron importer is more important for pathogenesis. Also, the double mutant was extremely attenuated for virulence, with no bacteria recovered from the spleen $24 \mathrm{~h}$ after IP injection and few recovered from lungs after intranasal inoculation (Brown et al., 2001a). These data suggest that Piu and Pia transporters function independently yet synergistically and that, although each can compensate for the loss of the other, Pia may be more important for the viability of the pneumococcus during invasive infection.

These differences in virulence attenuation suggest that (1) the single piu or pia mutants are still virulent, most likely due to the function of the second import system; and (2) the iron requirements and availability in the lungs differ greatly from those in the bloodstream (Figure 1). It may be that the pneumococcus requires both iron transporters during the initial infection in the lungs for invasion and systemic infection to occur. However, the precise iron requirements and iron level availability during nasal colonization remain to be determined. Also, the possibility of a third iron-uptake transporter system, which would explain the low attenuation of virulence of the single mutants in this study, was highlighted in a 2002 paper from the same group (Brown et al., 2002).

In further support of the iron-uptake defect, the single mutations in all three iron importers caused similar sensitivity to streptonigrin, and each was more resistant than was the WT (Brown et al., 2002). Furthermore, the triple mutant was highly resistant to high doses of the drug, up to $20 \mu \mathrm{g} / \mathrm{mL}$. Also, ${ }^{55} \mathrm{FeCl}_{3}$ uptake was severely impaired in the triple mutant compared to the piu/pia mutant strain. The small amount of iron import in the triple mutant may be from another unknown cation importer non-selectively pumping in iron. Since the iron import was additive, it was not surprising that the deletion of pit did not further decrease virulence in a pneumonia mouse model of infection but did slightly impair the mutant's ability to cause systemic infection. Also, adding the pit mutation to the double piu/pia strain did not increase the virulence attenuation in either form of infection. Finally, piaA was shown to be transcribed at a higher rate than any pit/piu components, consistent with the view that this is the dominant iron import system (Brown et al., 2002). Together, 
these data show the relative contributions and redundancies of the three iron import systems during pneumococcal infection.

The role of RitR in the pathogenesis of the D39 strain was tested via systemic intraperitoneal infection (Ong et al., 2013). Although the mice infected with $\Delta$ ritR had slightly increased survival times, all mice eventually succumbed to infection. Furthermore, no differences were detected in the concentration of bacteria in the blood $24 \mathrm{~h}$ after infection with either the WT or mutant strain. This outcome was also seen in an intranasal challenge mimicking pneumonia. These data suggest that RitR is not needed for pneumococcal survival in systemic or pneumonia murine models of infection, contrasting those previously published (Ulijasz et al., 2004). The differences in the strains used (i.e., encapsulated D39 vs. non-encapsulated R800) as well as the infection model system may account for these contrasting virulence results.

As discussed, Ong et al. determined that RitR regulated iron import and manganese, which was needed for protection against oxidative stress that can occur when iron levels are high (Ong et al., 2013). To further understand the impact of RitR on virulence, the virulent encapsulated D39 strain and an isogenic $\Delta$ ritR mutant were analyzed for their growth in media with differing Fe:Mn ratios. The data suggested that RitR expression is essential for the growth of pneumococci in high-Fe:low-Mn media and that $\mathrm{Mn}^{2+}$ may provide a protective advantage when $\mathrm{Fe}^{2+}$ levels are in excess (Ong et al., 2013). Therefore, the authors hypothesized that the Mn-dependent SodA may mediate growth restoration when $\mathrm{Mn}^{2+}$ levels increase, protecting the bacteria against superoxides generated in the cytosol when the concentration of $\mathrm{Fe}^{2+}$ is high. A sodA/ritR double mutant was constructed and analyzed in growth experiments. In high-Fe:low-Mn media, exogenous $\mathrm{Mn}^{2+}$ still restored growth, suggesting that the Mnmediated protection is not attributed to the oxidative protection of SodA. Regardless, these data suggest that $\mathrm{Mn}^{2+}$ can rescue the growth of the ritR mutant in high-Fe by reducing intracellular iron, and subsequently, oxidative stress.

\section{TARGETING IRON IMPORTERS FOR VACCINES}

The pneumococcal $A B C$ iron transporter systems elicit a strong antibody response during systemic infection, and these responses can protect against a pneumococcal infection (Brown et al., 2001b; Jomaa et al., 2005). This strategy has been used against many pathogens: in fact, iron import systems have previously been the target of a vaccine for Staphylococcus aureus (Ebert et al., 2010; Kim et al., 2010; Joshi et al., 2012; Pancari et al., 2012; Zapotoczna et al., 2013). Therefore, studies established by Brown et al. and expanded upon by Jomaa et al. used two of the iron import systems, Piu and Pia, as possible vaccine candidates (Brown et al., 2001b; Jomaa et al., 2005, 2006). Because PiuA and PiaA proteins are found in all pneumococcal serotypes tested, each protein was used (individually and together) to immunize mice for antibody responses and protection from subsequent pneumococcal challenge (Brown et al., 2001b). Specific antibody responses were detected against both proteins, with both PiuA and PiuA antibodies having cross-reactivity for each other. Although all of the mice immunized with adjuvant-only succumbed to the infection, both PiuA- and PiaA-immunized mice displayed improved survival, demonstrating that immunization with the iron import proteins increases survival rates and confers significant protection against systemic infection. As expected, immunization with both antigens further reduced the mortality rate. Passive immunization with antisera against PiaA-PiuA also significantly delayed time-to-death, indicating that immunization is at least partially antibody-mediated (Jomaa et al., 2005, 2006). Together, these data demonstrate that the lipoprotein components of two iron import systems can be used as a protein-based vaccine to protect against systemic pneumococcal infection.

In 2006, Whalan et al. determined that the piaA gene was $100 \%$ conserved in all typical pneumococci tested, which included 27 different serotypes, but was not found in any oral streptococci, including the closely related Streptococcus mitis (Whalan et al., 2006). However, piuA, was found in only 20 pneumococci serotypes, with a very low level of nucleotide divergence $(0.3 \%)$, and was also found in $S$. mitis and $S$. oralis, with a higher level of divergence (10\%). Regardless, these data further support the idea that PiuA and PiaA could be viable protein-vaccine candidates.

Evidence emerged in 2005 that PiuA and PiaA elicit a strong immune response in humans: patients with laboratoryconfirmed pneumococcal septicemia had elevated levels of antibodies directed against these two antigens in the convalescent phase of the infection but not in the acute phase (Whalan et al., 2005). This finding suggests that humans are exposed to PiuA and PiaA during systemic infection and mount antibody responses against these antigens, as occurs in infected mice. It also suggests that these two iron import proteins have the potential to be included in a protein-based vaccine. In the patient sera tested, eight different pneumococcal serotypes had specific antibody responses against PiuA and PiaA, demonstrating serotype-independent cross-reactivity. Also, both lipoproteins were immunogenic in healthy 7-month-old infants, suggesting that immunogenicity can be quickly established after birth, most likely through normal pneumococcal colonization of the nasopharynx (Whalan et al., 2005). These experimental and clinical observations indicate that targeting iron import may prove to be an effective vaccine strategy against the pneumococcus.

\section{COPPER}

Copper is toxic to a multitude of microorganisms, including bacteria, fungi, and viruses. Accordingly, operating rooms have begun using copper surfaces and surgical tools to reduce the risk of nosocomial infections (Salgado et al., 2013). To resist copper toxicity, bacteria have developed highly efficient copper export systems, many of which have important roles during infection as recently reviewed (Samanovic et al., 2012).

\section{THE CUPA COPPER EFFLUX SYSTEM}

S. pneumoniae has a highly conserved cop operon containing three genes: $\operatorname{cop} Y$, the operon regulator; $c u p A$, a copper transport protein with homology to a cupredoxin; and $\operatorname{cop} A$, the P-type ATPase copper exporter (Figure 1) (Shafeeq et al., 2011b). Several additional proteins have been identified as putative copper homeostasis proteins in S. pneumoniae (CutC, CtpC, and CtpE). Although these putative copper homeostasis proteins are upregulated during infection, they are not upregulated during copper 
stress, putting their precise function in S. pneumoniae into question (Shafeeq et al., 2011b). One possibility is that the relative abundance of other trace metals during infection is distinct to the in vitro media conditions used, resulting in increased expression. The precise function of these other proteins in copper homeostasis and pathogenesis remains unknown. It should also be noted that the mechanism of copper import in the pneumococcus has yet to be elucidated.

\section{REGULATORY CONTROL OF COPPER EFFLUX}

Transcriptional control of the cop operon in pneumococci is under the tight regulatory control of CopY, which represses the cop operon by binding the promoter region of the operon (Shafeeq et al., 2011b). Data obtained from other organisms show that once CopY binds copper, its affinity for DNA is greatly decreased, thus allowing transcription of the operon (Portmann et al., 2006). One atom of a metal inside the bacterial cell corresponds to $\sim 1.5 \mathrm{nM}$ concentration, assuming a bacterial volume of $\sim 10^{-15}$ liters per cell. CopY's affinity for copper has been estimated to be in the zeptomolar range $\left(10^{-21}\right)$ in other bacterial species, equating to less than one molecule of copper per bacterium and supporting the case that free intracellular copper is extremely detrimental to bacterial (Changela et al., 2003). Additionally, in other bacterial species, CopY controls expression of lactate oxidase, which can function to scavenge molecular oxygen (Barre et al., 2007). LctO is also involved in hydrogen peroxide production in streptococci (Kietzman and Caparon, 2010). It is unknown whether the pneumococcal CopY controls lctO expression or plays a role with $\mathrm{SpxB}$, which is encoded immediately downstream of the cop operon.

\section{MOLECULAR MECHANISM OF COPPER EFFLUX}

Recent structural data indicate that copper export is mediated by CupA transporting copper from the protein's low-affinity site to its high-affinity site (Shafeeq et al., 2011b; Fu et al., 2013). This system provides an extremely elegant model for the efficient trafficking of intracellular copper for efficient efflux because both CupA and CopA are membrane-anchored proteins (Fu et al., 2013). It remains unclear whether CupA and CopY interact to transfer the copper and precisely how the membrane-bound CupA acquires free copper inside the bacteria. The results of homology studies suggest that CupA has cupredoxin activity, reducing soluble $\mathrm{Cu}^{2+}$ to insoluble $\mathrm{Cu}^{1+}$, but direct evidence has not been shown (Fu et al., 2013). Pneumococcus can produce millimolar amounts of hydrogen peroxide, which reacts with $\mathrm{Cu}^{1+}$ to form water and free radicals via Fenton chemistry (Pericone et al., 2003). In theory, free-radical production could be circumvented by CupA sequestering $\mathrm{Cu}^{1+}$ after reduction and directly transferring it to CopA for export from the bacteria or by active uptake of glutathione, which converts hydrogen peroxide to water, thus relieving the stress of the free-radical formation by removing both precursors (Potter et al., 2012). The observation that glutathione uptake deficient pneumococci are more susceptible to copper stress supports this notion (Potter et al., 2012).

One of the major underlying questions about intracellular copper accumulation is the precise mechanism of toxicity. Recent data suggest that copper alone is not sufficient to cause oxidative damage in bacteria; therefore, it is not unreasonable that copper's toxic effects are mediated through another pathway (Macomber et al., 2007). Copper is very stable as represented in the Irving-Williams series, so it could displace metals in crucial bacterial enzymes, leading to their inactivity (Milicevic et al., 2011). Accordingly, copper negatively affects iron-sulfur clusters of dehydratases, inhibits branched chain amino acid biosynthesis, photosystem oxidase, and displaces manganese in SOD as additional mechanisms of toxicity (Batinic-Haberle et al., 1997; Macomber and Imlay, 2009; Azzouzi et al., 2013). Ribonucleotide reductase protein, NrdF, and coupled factor NrdE are both necessary for the aerobic nucleotide synthesis pathway in pneumococci and may interact with copper, as may other proteins involved in aerobic nucleotide synthesis, such as NrdI (Sun et al., 2011). Thus, it is also possible that copper is causing toxicity by inhibiting nucleotide synthesis or other essential metabolic processes.

\section{COPPER AND PATHOGENESIS}

Proteins involved in copper homeostasis have been implicated at multiple stages of pneumococcal pathogenesis. The inability of the pneumococcus to functionally export copper is detrimental to the cell, with $\triangle \operatorname{cop} A$ mutants being more susceptible to copper toxicity than are wild-type bacteria (Shafeeq et al., 2011b; Fu et al., 2013). Mice intranasally infected with $\Delta \operatorname{cop} A$ mutants have an increased survival rate, likely due to the mutant's inability to grow in the host's nasopharynx (Shafeeq et al., 2011b). The results of signature-tagged mutagenesis screening and transposon sequencing implicate CopA involvement in pneumococcal fitness in both the nasopharynx and the lung (Hava and Camilli, 2002; van Opijnen and Camilli, 2012). Virulence data for the $\Delta \operatorname{cop} Y$ and $\triangle c u p A$ mutants are unavailable, however, transposon sequencing results indicate that no significant defects in either lung infection or nasopharyngeal colonization would occur when these genes are disrupted (van Opijnen and Camilli, 2012). This finding is in agreement with previous findings that $\Delta \operatorname{cop} Y$ mutants have wild-type tolerance of copper, $\triangle c u p A$ mutants have a similar tolerance to that of $\triangle c o p A$ mutants depending on the media, and $\triangle c u p A$ and $\triangle c o p Y$ mutations have little or no effect on virulence, respectively (Shafeeq et al., 2011b; Fu et al., 2013).

The attenuation of the $\triangle \operatorname{cop} A$ mutant during infection may be partially explained by the activity of the ATP7a copper transporter expressed in macrophages and other cells because this strain is unable to export copper. ATP7a has been implicated in the elimination of pathogens via importing excess copper into the phagolysosome to mediate more-effective bacterial killing (White et al., 2009). Deletion of ATP7a in murine models resulted in severe growth defects and premature death, making investigation into susceptibility to infection difficult (Wang et al., 2012b). Advances into the role of ATP7a will be facilitated by the recent cell line-specific conditional knockouts of this transporter in murine systems (Wang et al., 2012a,b). Such tools will allow for refined investigations into the role of this copper transporter during the progression of infection. Another major question that remains unanswered is why the pneumococcus uptakes copper at all. Copper-dependent enzymes have not been found, yet the amount of intracellular copper and the universal conservation of dedicated export machinery indicate that a copper acquisition 
system may exist. Future studies of the precise molecular interactions that facilitate efficient copper export and of the precise role of cop operons and other predicted copper homeostasis pathways will provide insight into the essential copper homeostasis pathways.

\section{ZINC}

In contrast to copper's toxicity in S. pneumoniae, zinc has both beneficial and detrimental effects in bacteria, with several classes of bacterial proteins, such as metalloproteases and transcriptional regulators, relying on zinc for function although high concentrations of zinc are toxic (Guerra et al., 2011; McDevitt et al., 2011; Milicevic et al., 2011; Bek-Thomsen et al., 2012; Menon and Govindarajan, 2013). In a recent review, Shafeeq et al. comprehensively outline the literature on zinc's homeostasis, transport, and involvement in the pathogenesis of streptococci (Shafeeq et al., 2013). During infection, the phagolysosomes of macrophages either sequester zinc, reducing the bacteria's ability to use zinc for essential cellular processes, or overwhelm bacteria with zinc, leading to toxicity (Kehl-Fie and Skaar, 2010; Botella et al., 2011). Switching between these innate immune responses may be due to the perceived level of toxicity of the bacteria, however, further investigation would be needed to understand the exact mechanisms (Botella et al., 2011). To account for both situations inside the host, $S$. pneumoniae have zinc influx and efflux pumps.

\section{ZINC ACQUISITION}

S. pneumoniae encodes five proteins directly involved in zinc acquisition: zinc importers AdcA and AdcAII, permease AdcB, ATPase AdcC, and transcription regulator AdcR (Figure 1) (Dintilhac and Claverys, 1997; Dintilhac et al., 1997; Bayle et al., 2011). The transporters AdcA and AdcAII have overlapping specificity for zinc in vitro, and the combined $\triangle a d c A / \triangle a d c A I I$ mutant is deficient in zinc uptake. Furthermore, strains having deletions of both genes have deficiencies in growth in low-zinc environments and have severe colonization defects in intranasal and intraperitoneal infection models (Bayle et al., 2011). Deletion of the permease AdcB also confers deficiency in growth in lowzinc environments, with a slight defect in growth under normal conditions as well.

The Pht family of proteins (PhtA, PhtB, PhtD, and PhtE) may also be involved in zinc homeostasis. These proteins are upregulated in the presence of excess zinc but are under the control of AdcR (Ogunniyi et al., 2009; Shafeeq et al., 2011a). The single $\Delta p h t D$ mutation does not affect zinc uptake or growth, but the mutation of all four Pht proteins increases growth in the presence of excess zinc, leading to the suggestion that these proteins may be zinc scavengers or involved in zinc uptake. However, the results of direct binding assays involving these proteins and zinc have not been published (Bayle et al., 2011; Rioux et al., 2011).

\section{ZINC EFFLUX}

In levels of zinc that are higher than equilibrium, S. pneumoniae mediates resistance to zinc toxicity by upregulating proteins such as AdhC, a glutathione-dependent alcohol dehydrogenase, and $\mathrm{CzcD}$, a zinc export system protein in the cation diffusion facilitator family, both of which defend against the reactive nitrogen byproducts of zinc (Kidd et al., 2007; Kloosterman et al., 2007; Kimaro Mlacha et al., 2013; Shafeeq et al., 2013). Gene transcript levels of $c z c D$ and $a d h C$ are elevated in more-invasive strains of pneumococcus, such as TIGR4, and although initial reports showed that AdhC was essential for lung infection, it has since been shown that neither $c z c D$ nor adhC contribute to overall pathogenesis (Hava and Camilli, 2002; van Opijnen and Camilli, 2012; Kimaro Mlacha et al., 2013). However, just as it does with zinc import, S. pneumoniae may have overlapping functionality in zinc efflux, in which case single mutations may not yield discernible phenotypes under general conditions.

\section{OTHER TRANSITION METALS}

Although little is known about the role of cobalt, nickel, and other transition metals not already mentioned in this review, it is likely that these metals can also enter the bacterium, so S. pneumoniae likely possesses the ability to export these metals. Several uncharacterized putative E1-E2 P-type ATPases exist in the $S$. pneumoniae genome that could facilitate import or export these additional transition metals. The $c z c$ locus has been shown to mediate cobalt and cadmium resistance in other organisms, however, there is no direct evidence of such activity in S. pneumoniae (Nies, 1992). Nevertheless, $c z c D$ transcript levels are upregulated in the presence of both cobalt and nickel, implying that $\mathrm{CzcD}$ could indeed be exporting these metals. Additionally, Sun et al. have described a group of proteins that likely bind cobalt and nickel, with the cobalt-binding proteins found in ribosomal structures and having RNA binding and structural activity and the nickel-binding proteins having ligase activity (Sun et al., 2013). However, the roles of these transporters in pneumococcal metabolism and virulence have not been determined. Cobalamin (vitamin B12) is a cobalt-binding compound that some intestinal bacteria use, however, no evidence exists that $S$. pneumoniae uses vitamin B12 (Giannella et al., 1971). It should also be noted that the pneumococci encode numerous additional ABC transporters and putative efflux systems, although the substrates of these systems and their roles during infection remain unknown.

\section{CONCLUSIONS}

The environments encountered by the pneumococcus in the human body during both colonization and infection vary greatly in terms of the bioavailability of trace metals used as co-factors by both host and pathogen. As such, metal homeostasis is vital not only to fight bacterial infections but also to survival of the pathogen. Building upon our understanding of the metal import and export machinery of $S$. pneumoniae not only improves basic science knowledge of metal trafficking and usage in the bacteria but also offers additional therapeutic targets for inhibiting bacterial infections. Because many of the metal acquisition systems of the pneumococcus are both surface-exposed and important for invasive infection, they remain attractive vaccine candidates for protein-based vaccines. Another potential avenue for future therapeutics would be compounds that specifically target these essential bacterial uptake and efflux systems. The feasibility of this approach was recently demonstrated in Staphylococcus aureus, whereby using small molecules to activate the regulatory system 
controlling heme uptake perturbed the central metabolism and was toxic to the bacterium (Mike et al., 2013). Extension of such screens to other essential metal homeostasis systems may provide a new avenue for novel therapeutics to target bacterial pathogens.

\section{REFERENCES}

Andreini, C., Bertini, I., Cavallaro, G., Holliday, G. L., and Thornton, J. M. (2008). Metal ions in biological catalysis: from enzyme databases to general principles. J. Biol. Inorg. Chem. 13, 1205-1218. doi: 10.1007/s00775-008-0404-5

Azzouzi, A., Steunou, A. S., Durand, A., Khalfaoui-Hassani, B., Bourbon, M. L., Astier, C., et al. (2013). Coproporphyrin III excretion identifies the anaerobic coproporphyrinogen III oxidase $\mathrm{HemN}$ as a copper target in the $\mathrm{Cu}$ -ATPase mutant copA of Rubrivivax gelatinosus. Mol. Microbiol. 88, 339-351. doi: $10.1111 / \mathrm{mmi} .12188$

Balogun, R. A., Ogunniyi, A., Sanford, K., Okafor, C., Lobo, P. I., Siami, G., et al. (2010). Therapeutic apheresis in special populations. J. Clin. Apher. 25, 265-274. doi: $10.1002 /$ jca. 20250

Barre, O., Mourlane, F., and Solioz, M. (2007). Copper induction of lactate oxidase of Lactococcus lactis: a novel metal stress response. J. Bacteriol. 189, 5947-5954. doi: 10.1128/JB.00576-07

Batinic-Haberle, I., Liochev, S. I., Spasojevic, I., and Fridovich, I. (1997). A potent superoxide dismutase mimic: manganese beta-octabromo-meso-tetrakis- $(\mathrm{N}$ methylpyridinium-4-yl) porphyrin. Arch. Biochem. Biophys. 343, 225-233. doi: 10.1006/abbi.1997.0157

Bayle, L., Chimalapati, S., Schoehn, G., Brown, J., Vernet, T., and Durmort, C. (2011). Zinc uptake by Streptococcus pneumoniae depends on both AdcA and AdcAII and is essential for normal bacterial morphology and virulence. Mol. Microbiol. 82, 904-916. doi: 10.1111/j.1365-2958.2011.07862.x

Bek-Thomsen, M., Poulsen, K., and Kilian, M. (2012). Occurrence and evolution of the paralogous zinc metalloproteases IgAl protease, $\mathrm{ZmpB}, \mathrm{ZmpC}$, and $\mathrm{ZmpD}$ in Streptococcus pneumoniae and related commensal species. MBio 3, e00303-e00312. doi: 10.1128/mBio.00303-12

Berntsson, R. P., Smits, S. H., Schmitt, L., Slotboom, D. J., and Poolman, B. (2010). A structural classification of substrate-binding proteins. FEBS Lett. 584, 2606-2617. doi: 10.1016/j.febslet.2010.04.043

Berry, A. M., and Paton, J. C. (1996). Sequence heterogeneity of PsaA, a $37-$ kilodalton putative adhesin essential for virulence of Streptococcus pneumoniae. Infect. Immun. 64, 5255-5262.

Berry, E. A., and Trumpower, B. L. (1987). Simultaneous determination of hemes a, b, and c from pyridine hemochrome spectra. Anal. Biochem. 161, 1-15. doi: 10.1016/0003-2697(87)90643-9

Botella, H., Peyron, P., Levillain, F., Poincloux, R., Poquet, Y., Brandli, I., et al. (2011). Mycobacterial p(1)-type ATPases mediate resistance to zinc poisoning in human macrophages. Cell Host Microbe 10, 248-259. doi: 10.1016/j.chom.2011.08.006

Briles, D. E., Ades, E., Paton, J. C., Sampson, J. S., Carlone, G. M., Huebner, R. C., et al. (2000). Intranasal immunization of mice with a mixture of the pneumococcal proteins PsaA and PspA is highly protective against nasopharyngeal carriage of Streptococcus pneumoniae. Infect. Immun. 68, 796-800. doi: 10.1128/IAI.68.2.796-800.2000

Brown, J. S., Gilliland, S. M., and Holden, D. W. (2001a). A Streptococcus pneumoniae pathogenicity island encoding an $\mathrm{ABC}$ transporter involved in iron uptake and virulence. Mol. Microbiol. 40, 572-585. doi: 10.1046/j.13652958.2001.02414.x

Brown, J. S., Ogunniyi, A. D., Woodrow, M. C., Holden, D. W., and Paton, J. C. (2001b). Immunization with components of two iron uptake ABC transporters protects mice against systemic Streptococcus pneumoniae infection. Infect. Immun. 69, 6702-6706. doi: 10.1128/IAI.69.11.6702-6706.2001

Brown, J. S., Gilliland, S. M., Ruiz-Albert, J., and Holden, D. W. (2002). Characterization of pit, a Streptococcus pneumoniae iron uptake ABC transporter. Infect. Immun. 70, 4389-4398. doi: 10.1128/IAI.70.8.4389-4398.2002

Changela, A., Chen, K., Xue, Y., Holschen, J., Outten, C. E., O’Halloran, T. V., et al. (2003). Molecular basis of metal-ion selectivity and zeptomolar sensitivity by CueR. Science 301, 1383-1387. doi: 10.1126/science.1085950

Cheng, W., Li, Q., Jiang, Y. L., Zhou, C. Z., and Chen, Y. (2013). Structures of Streptococcus pneumoniae PiaA and its complex with ferrichrome reveal insights into the substrate binding and release of high affinity iron transporters. PLoS ONE 8:e71451. doi: 10.1371/journal.pone.0071451
Corbin, B. D., Seeley, E. H., Raab, A., Feldmann, J., Miller, M. R., Torres, V. J., et al. (2008). Metal chelation and inhibition of bacterial growth in tissue abscesses. Science 319, 962-965. doi: 10.1126/science.1152449

Counago, R. M., Ween, M. P., Begg, S. L., Bajaj, M., Zuegg, J., O’Mara, M. L., et al. (2013). Imperfect coordination chemistry facilitates metal ion release in the Psa permease. Nat. Chem. Biol. doi: 10.1038/nchembio.1382. [Epub ahead of print].

Crosa, J. H., Mey, A. R., and Payne, S. M. (2004). Iron Transport in Bacteria. Washington, DC: American Society for Microbiology Press.

Daly, M. J., Gaidamakova, E. K., Matrosova, V. Y., Vasilenko, A., Zhai, M., Venkateswaran, A., et al. (2004). Accumulation of $\mathrm{Mn}$ (II) in Deinococcus radiodurans facilitates gamma-radiation resistance. Science 306, 1025-1028. doi: 10.1126/science. 1103185

De Domenico, I., McVey Ward, D., and Kaplan, J. (2008). Regulation of iron acquisition and storage: consequences for iron-linked disorders. Nat. Rev. Mol. Cell Biol. 9, 72-81. doi: 10.1038/nrm2295

Dintilhac, A., Alloing, G., Granadel, C., and Claverys, J. P. (1997). Competence and virulence of Streptococcus pneumoniae: Adc and PsaA mutants exhibit a requirement for $\mathrm{Zn}$ and $\mathrm{Mn}$ resulting from inactivation of putative $\mathrm{ABC}$ metal permeases. Mol. Microbiol. 25, 727-739. doi: 10.1046/j.1365-2958.1997.5111879.x

Dintilhac, A., and Claverys, J. P. (1997). The adc locus, which affects competence for genetic transformation in Streptococcus pneumoniae, encodes an ABC transporter with a putative lipoprotein homologous to a family of streptococcal adhesins. Res. Microbiol. 148, 119-131. doi: 10.1016/S0923-2508(97)87643-7

Dudev, T., and Lim, C. (2008). Metal binding affinity and selectivity in metalloproteins: insights from computational studies. Annu. Rev. Biophys. 37, 97-116. doi: 10.1146/annurev.biophys.37.032807.125811

Ebert, T., Smith, S., Pancari, G., Clark, D., Hampton, R., Secore, S., et al. (2010). A fully human monoclonal antibody to Staphylococcus aureus iron regulated surface determinant B (IsdB) with functional activity in vitro and in vivo. Hum. Antibodies 19, 113-128. doi: 10.3233/HAB-2010-0235

Echave, P., Tamarit, J., Cabiscol, E., and Ros, J. (2003). Novel antioxidant role of alcohol dehydrogenase E from Escherichia coli. J. Biol. Chem. 278, 30193-30198. doi: 10.1074/jbc.M304351200

Forbes, J. R., and Gros, P. (2003). Iron, manganese, and cobalt transport by Nramp1 (Slc11a1) and Nramp2 (Slc1la2) expressed at the plasma membrane. Blood 102, 1884-1892. doi: 10.1182/blood-2003-02-0425

Fu, Y., Tsui, H. C., Bruce, K. E., Sham, L. T., Higgins, K. A., Lisher, J. P., et al. (2013). A new structural paradigm in copper resistance in Streptococcus pneumoniae. Nat. Chem. Biol. 9, 177-183. doi: 10.1038/nchembio.1168

Giannella, R. A., Broitman, S. A., and Zamcheck, N. (1971). Vitamin B12 uptake by intestinal microorganisms: mechanism and relevance to syndromes of intestinal bacterial overgrowth. J. Clin. Invest. 50, 1100-1107. doi: 10.1172/JCI106581

Gray-Owen, S. D., and Schryvers, A. B. (1996). Bacterial transferrin and lactoferrin receptors. Trends Microbiol. 4, 185-191. doi: 10.1016/0966-842X(96) 10025-1

Grollman, A. P., and Moriya, M. (1993). Mutagenesis by 8-oxoguanine: an enemy within. Trends Genet. 9, 246-249. doi: 10.1016/0168-9525(93)90089-Z

Guerra, A. J., Dann, C. E. 3rd., and Giedroc, D. P. (2011). Crystal structure of the zinc-dependent MarR family transcriptional regulator AdcR in the $\mathrm{Zn}$ (II)bound state. J. Am. Chem. Soc. 133, 19614-19617. doi: 10.1021/ja2080532

Haley, K. P., and Skaar, E. P. (2012). A battle for iron: host sequestration and Staphylococcus aureus acquisition. Microbes Infect. 14, 217-227. doi: 10.1016/j.micinf.2011.11.001

Hargrove, M. S., Whitaker, T., Olson, J. S., Vali, R. J., and Mathews, A. J. (1997). Quaternary structure regulates hemin dissociation from human hemoglobin. J. Biol. Chem. 272, 17385-17389. doi: 10.1074/jbc.272. 28.17385

Hassan, H. M. (1989). Microbial superoxide dismutases. Adv. Genet. 26, 65-97. doi: 10.1016/S0065-2660(08)60223-0

Hava, D. L., and Camilli, A. (2002). Large-scale identification of serotype 4 Streptococcus pneumoniae virulence factors. Mol. Microbiol. 45, 1389-1406. doi: 10.1046/j.1365-2958.2002.03106.x

Heinemann, I. U., Jahn, M., and Jahn, D. (2008). The biochemistry of heme biosynthesis. Arch. Biochem. Biophys. 474, 238-251. doi: 10.1016/j.abb.2008.02.015

Hibbing, M. E., Fuqua, C., Parsek, M. R., and Peterson, S. B. (2010). Bacterial competition: surviving and thriving in the microbial jungle. Nat. Rev. Microbiol. 8, 15-25. doi: 10.1038/nrmicro2259

Honsa, E. S., and Maresso, A. W. (2011). Mechanisms of iron import in anthrax. Biometals 24, 533-545. doi: 10.1007/s10534-011-9413-x 
Hoskins, J., Alborn, W. E. Jr., Arnold, J., Blaszczak, L. C., Burgett, S., Dehoff, B. S., et al. (2001). Genome of the bacterium Streptococcus pneumoniae strain R6. J. Bacteriol. 183, 5709-5717. doi: 10.1128/JB.183.19.5709-5717.2001

Jabado, N., Jankowski, A., Dougaparsad, S., Picard, V., Grinstein, S., and Gros, P. (2000). Natural resistance to intracellular infections: natural resistanceassociated macrophage protein $1(\mathrm{Nramp} 1)$ functions as a $\mathrm{pH}$-dependent manganese transporter at the phagosomal membrane. J. Exp. Med. 192, 1237-1248. doi: 10.1084/jem.192.9.1237

Jacobsen, F. E., Kazmierczak, K. M., Lisher, J. P., Winkler, M. E., and Giedroc, D. P. (2011). Interplay between manganese and zinc homeostasis in the human pathogen Streptococcus pneumoniae. Metallomics 3, 38-41. doi: 10.1039/c0mt00050g

Johnston, J. W., Briles, D. E., Myers, L. E., and Hollingshead, S. K. (2006). Mn2+dependent regulation of multiple genes in Streptococcus pneumoniae through PsaR and the resultant impact on virulence. Infect. Immun. 74, 1171-1180. doi: 10.1128/IAI.74.2.1171-1180.2006

Jomaa, M., Terry, S., Hale, C., Jones, C., Dougan, G., and Brown, J. (2006). Immunization with the iron uptake $\mathrm{ABC}$ transporter proteins PiaA and PiuA prevents respiratory infection with Streptococcus pneumoniae. Vaccine 24, 5133-5139. doi: 10.1016/j.vaccine.2006.04.012

Jomaa, M., Yuste, J., Paton, J. C., Jones, C., Dougan, G., and Brown, J. S. (2005). Antibodies to the iron uptake ABC transporter lipoproteins PiaA and PiuA promote opsonophagocytosis of Streptococcus pneumoniae. Infect. Immun. 73, 6852-6859. doi: 10.1128/IAI.73.10.6852-6859.2005

Joshi, A., Pancari, G., Cope, L., Bowman, E. P., Cua, D., Proctor, R. A., et al. (2012). Immunization with Staphylococcus aureus iron regulated surface determinant B (IsdB) confers protection via Th17/IL17 pathway in a murine sepsis model. Hum. Vaccin. Immunother. 8, 336-346. doi: 10.4161/hv.18946

Kehl-Fie, T. E., and Skaar, E. P. (2010). Nutritional immunity beyond iron: a role for manganese and zinc. Curr. Opin. Chem. Biol. 14, 218-224. doi: 10.1016/j.cbpa.2009.11.008

Kidd, S. P., Jiang, D., Jennings, M. P., and McEwan, A. G. (2007). Glutathionedependent alcohol dehydrogenase AdhC is required for defense against nitrosative stress in Haemophilus influenzae. Infect. Immun. 75, 4506-4513. doi: 10.1128/IAI.00487-07

Kietzman, C. C., and Caparon, M. G. (2010). CcpA and LacD.1 affect temporal regulation of Streptococcus pyogenes virulence genes. Infect. Immun. 78, 241-252. doi: 10.1128/IAI.00746-09

Kim, H. K., Dedent, A., Cheng, A. G., McAdow, M., Bagnoli, F., Missiakas, D. M., et al. (2010). IsdA and IsdB antibodies protect mice against Staphylococcus aureus abscess formation and lethal challenge. Vaccine 28, 6382-6392. doi: 10.1016/j.vaccine.2010.02.097

Kimaro Mlacha, S. Z., Romero-Steiner, S., Dunning Hotopp, J. C., Kumar, N., Ishmael, N., Riley, D. R., et al.. (2013). Phenotypic, gen et al.,omic, and transcriptional characterization of Streptococcus pneumoniae interacting with human pharyngeal cells. BMC Genomics 14:383. doi: 10.1186/ 1471-2164-14-383

Kloosterman, T. G., van der Kooi-Pol, M. M., Bijlsma, J. J., and Kuipers, O. P. (2007). The novel transcriptional regulator SczA mediates protection against $\mathrm{Zn} 2+$ stress by activation of the $\mathrm{Zn} 2+$-resistance gene $\mathrm{czcD}$ in Streptococcus pneumoniae. Mol. Microbiol. 65, 1049-1063. doi: 10.1111/j.13652958.2007.05849.x

Kloosterman, T. G., Witwicki, R. M., van der Kooi-Pol, M. M., Bijlsma, J. J., and Kuipers, O. P. (2008). Opposite effects of $\mathrm{Mn} 2+$ and $\mathrm{Zn} 2+$ on PsaR-mediated expression of the virulence genes pcpA, prtA, and psaBCA of Streptococcus pneumoniae. J. Bacteriol. 190, 5382-5393. doi: 10.1128/JB.00307-08

Lange, R., Wagner, C., de Saizieu, A., Flint, N., Molnos, J., Stieger, M., et al. (1999). Domain organization and molecular characterization of 13 two-component systems identified by genome sequencing of Streptococcus pneumoniae. Gene 237, 223-234. doi: 10.1016/S0378-1119(99) 00266-8

Lanie, J. A., Ng, W. L., Kazmierczak, K. M., Andrzejewski, T. M., Davidsen, T. M., Wayne, K. J., et al. (2007). Genome sequence of Avery's virulent serotype 2 strain D39 of Streptococcus pneumoniae and comparison with that of unencapsulated laboratory strain R6. J. Bacteriol. 189, 38-51. doi: 10.1128/JB.01148-06

Lau, G. W., Haataja, S., Lonetto, M., Kensit, S. E., Marra, A., Bryant, A. P., et al. (2001). A functional genomic analysis of type 3 Streptococcus pneumoniae virulence. Mol. Microbiol. 40, 555-571. doi: 10.1046/j.1365-2958. 2001.02335.x
Lisher, J. P., Higgins, K. A., Maroney, M. J., and Giedroc, D. P. (2013). Physical characterization of the manganese-sensing pneumococcal surface antigen repressor from Streptococcus pneumoniae. Biochemistry. doi: 10.1021/bi401132w. [Epub ahead of print].

Macomber, L., and Imlay, J. A. (2009). The iron-sulfur clusters of dehydratases are primary intracellular targets of copper toxicity. Proc. Natl. Acad. Sci. U.S.A. 106, 8344-8349. doi: 10.1073/pnas.0812808106

Macomber, L., Rensing, C., and Imlay, J. A. (2007). Intracellular copper does not catalyze the formation of oxidative DNA damage in Escherichia coli. J. Bacteriol. 189, 1616-1626. doi: 10.1128/JB.01357-06

Marra, A., Lawson, S., Asundi, J. S., Brigham, D., and Hromockyj, A. E. (2002). In vivo characterization of the psa genes from Streptococcus pneumoniae in multiple models of infection. Microbiology 148, 1483-1491.

McCord, J. M., and Fridovich, I. (1969). Superoxide dismutase. An enzymic function for erythrocuprein (hemocuprein). J. Biol. Chem. 244, 6049-6055.

McDevitt, C. A., Ogunniyi, A. D., Valkov, E., Lawrence, M. C., Kobe, B., McEwan, A. G., et al. (2011). A molecular mechanism for bacterial susceptibility to zinc. PLoS Pathog. 7:e1002357. doi: 10.1371/journal.ppat.1002357

Menon, B. B., and Govindarajan, B. (2013). Identification of an atypical zinc metalloproteinase, ZmpC, from an epidemic conjunctivitis-causing strain of Streptococcus pneumoniae. Microb. Pathog. 56, 40-46. doi: 10.1016/j.micpath.2012.11.006

Michaels, M. L., Tchou, J., Grollman, A. P., and Miller, J. H. (1992). A repair system for 8-oxo-7,8-dihydrodeoxyguanine. Biochemistry 31, 10964-10968. doi: 10.1021/bi00160a004

Mike, L. A., Dutter, B. F., Stauff, D. L., Moore, J. L., Vitko, N. P., Aranmolate, O., et al. (2013). Activation of heme biosynthesis by a small molecule that is toxic to fermenting Staphylococcus aureus. Proc. Natl. Acad. Sci. U.S.A. 110, 8206-8211. doi: 10.1073/pnas.1303674110

Milicevic, A., Branica, G., and Raos, N. (2011). Irving-Williams order in the framework of connectivity index (3)chiv enables simultaneous prediction of stability constants of bivalent transition metal complexes. Molecules 16, 1103-1112. doi: 10.3390/molecules 16021103

Nanduri, B., Shah, P., Ramkumar, M., Allen, E. B., Swiatlo, E., Burgess, S. C., et al. (2008). Quantitative analysis of Streptococcus pneumoniae TIGR4 response to in vitro iron restriction by 2-D LC ESI MS/MS. Proteomics 8, 2104-2114. doi: 10.1002/pmic. 200701048

Nies, D. H. (1992). CzcR and CzcD, gene products affecting regulation of resistance to cobalt, zinc, and cadmium (czc system) in Alcaligenes eutrophus. J. Bacteriol. $174,8102-8110$.

Novak, R., Braun, J. S., Charpentier, E., and Tuomanen, E. (1998). Penicillin tolerance genes of Streptococcus pneumoniae: the ABC-type manganese permease complex Psa. Mol. Microbiol. 29, 1285-1296. doi: 10.1046/j.13652958.1998.01016.x

Ogunniyi, A. D., Folland, R. L., Briles, D. E., Hollingshead, S. K., and Paton, J. C. (2000). Immunization of mice with combinations of pneumococcal virulence proteins elicits enhanced protection against challenge with Streptococcus pneumoniae. Infect. Immun. 68, 3028-3033. doi: 10.1128/IAI.68.5. 3028-3033.2000

Ogunniyi, A. D., Grabowicz, M., Mahdi, L. K., Cook, J., Gordon, D. L., Sadlon, T. A., et al. (2009). Pneumococcal histidine triad proteins are regulated by the $\mathrm{Zn} 2+-$ dependent repressor AdcR and inhibit complement deposition through the recruitment of complement factor H. FASEB J. 23, 731-738. doi: 10.1096/fj.08119537

Ong, C. L., Potter, A. J., Trappetti, C., Walker, M. J., Jennings, M. P., Paton, J. C., et al. (2013). Interplay between manganese and iron in pneumococcal pathogenesis: role of the orphan response regulator RitR. Infect. Immun. 81, 421-429. doi: 10.1128/IAI.00805-12

Pancari, G., Fan, H., Smith, S., Joshi, A., Haimbach, R., Clark, D., et al. (2012). Characterization of the mechanism of protection mediated by CSD7, a monoclonal antibody to Staphylococcus aureus iron regulated surface determinant B (IsdB). Front. Cell. Infect. Microbiol. 2:36. doi: 10.3389/fcimb. 2012.00036

Panek, H., and O'Brian, M. R. (2002). A whole genome view of prokaryotic haem biosynthesis. Microbiology 148, 2273-2282.

Paton, J.C. (1998). Novel pneumococcal surface proteins: role in virulence and vaccine potential. Trends Microbiol. 6, 85-87; discussion 87-88. doi: 10.1016/S0966842X(98)01220-7 
Pericone, C. D., Park, S., Imlay, J. A., and Weiser, J. N. (2003). Factors contributing to hydrogen peroxide resistance in Streptococcus pneumoniae include pyruvate oxidase $(\mathrm{SpxB})$ and avoidance of the toxic effects of the fenton reaction. J. Bacteriol. 185, 6815-6825. doi: 10.1128/JB.185.23. 6815-6825.2003

Pintor, M., Gomez, J. A., Ferron, L., Ferreiros, C. M., and Criado, M. T. (1998). Analysis of TbpA and TbpB functionality in defective mutants of Neisseria meningitidis. J. Med. Microbiol. 47, 757-760. doi: 10.1099/00222615-47-9-757

Portmann, R., Poulsen, K. R., Wimmer, R., and Solioz, M. (2006). CopY-like copper inducible repressors are putative 'winged helix' proteins. Biometals 19, 61-70. doi: 10.1007/s10534-005-5381-3

Potter, A. J., Trappetti, C., and Paton, J. C. (2012). Streptococcus pneumoniae uses glutathione to defend against oxidative stress and metal ion toxicity. J. Bacteriol. 194, 6248-6254. doi: 10.1128/JB.01393-12

Pulliainen, A. T., Haataja, S., Kahkonen, S., and Finne, J. (2003). Molecular basis of $\mathrm{H} 2 \mathrm{O} 2$ resistance mediated by Streptococcal Dpr. Demonstration of the functional involvement of the putative ferroxidase center by sitedirected mutagenesis in Streptococcus suis. J. Biol. Chem. 278, 7996-8005. doi: 10.1074/jbc.M210174200

Rioux, S., Neyt, C., Di Paolo, E., Turpin, L., Charland, N., Labbe, S., et al. (2011). Transcriptional regulation, occurrence and putative role of the Pht family of Streptococcus pneumoniae. Microbiology 157, 336-348. doi: 10.1099/mic.0.042184-0

Robbins, J. B., Austrian, R., Lee, C. J., Rastogi, S. C., Schiffman, G., Henrichsen, J., et al. et al. (1983). Considerations for formulating the secondgeneration pneumococcal capsular polysaccharide vaccine with emphasis on the cross-reactive types within groups. J. Infect. Dis. 148, 1136-1159. doi: 10.1093/infdis/148.6.1136

Robbins, J. B., and Schneerson, R. (1983). Planning for a second (23 valent) generation pneumococcal vaccine. With special reference to new developments in our understanding of the structure and biology of polysaccharides. Bull. Eur. Physiopathol. Respir. 19, 215-226.

Romero-Espejel, M. E., Gonzalez-Lopez, M. A., and Olivares-Trejo Jde, J. (2013). Streptococcus pneumoniae requires iron for its viability and expresses two membrane proteins that bind haemoglobin and haem. Metallomics 5, 384-389. doi: $10.1039 / \mathrm{c} 3 \mathrm{mt} 20244 \mathrm{e}$

Rosch, J. W., Gao, G., Ridout, G., Wang, Y. D., and Tuomanen, E. I. (2009). Role of the manganese efflux system mntE for signalling and pathogenesis in Streptococcus pneumoniae. Mol. Microbiol. 72, 12-25. doi: 10.1111/j.13652958.2009.06638.x

Salgado, C. D., Sepkowitz, K.A., John, J. F., Cantey, J. R., Attaway, H. H., Freeman, K. D., et al. (2013). Copper surfaces reduce the rate of healthcare-acquired infections in the intensive care unit. Infect. Control Hosp. Epidemiol. 34, 479-486. doi: $10.1086 / 670207$

Samanovic, M. I., Ding, C., Thiele, D. J., and Darwin, K. H. (2012). Copper in microbial pathogenesis: meddling with the metal. Cell Host Microbe 11, 106-115. doi: 10.1016/j.chom.2012.01.009

Samrakandi, M. M., and Pasta, F. (2000). Hyperrecombination in Streptococcus pneumoniae depends on an atypical mutY homologue. J. Bacteriol. 182, 3353-3360. doi: 10.1128/JB.182.12.3353-3360.2000

Shafeeq, S., Kloosterman, T. G., and Kuipers, O. P. (2011a). Transcriptional response of Streptococcus pneumoniae to $\mathrm{Zn} 2+$ ) limitation and the repressor/activator function of AdcR. Metallomics 3, 609-618. doi: $10.1039 / \mathrm{clmt00030f}$

Shafeeq, S., Yesilkaya, H., Kloosterman, T. G., Narayanan, G., Wandel, M., Andrew, P. W., et al. (2011b). The cop operon is required for copper homeostasis and contributes to virulence in Streptococcus pneumoniae. Mol. Microbiol. 81, 1255-1270. doi: 10.1111/j.1365-2958.2011.07758.x

Shafeeq, S., Kuipers, O. P., and Kloosterman, T. G. (2013). The role of zinc in the interplay between pathogenic streptococci and their hosts. Mol. Microbiol. 88, 1047-1057. doi: $10.1111 / \mathrm{mmi} .12256$

Spellerberg, B., Cundell, D. R., Sandros, J., Pearce, B. J., Idanpaan-Heikkila, I., Rosenow, C., et al. (1996). Pyruvate oxidase, as a determinant of virulence in Streptococcus pneumoniae. Mol. Microbiol. 19, 803-813. doi: 10.1046/j.13652958.1996.425954.x

Sun, X., Xiao, C. L., Ge, R., Yin, X., Li, H., Li, N., et al. (2011). Putative copperand zinc-binding motifs in Streptococcus pneumoniae identified by immobilized metal affinity chromatography and mass spectrometry. Proteomics 11, 3288-3298. doi: 10.1002/pmic.201000396
Sun, X., Yu, G., Xu, Q., Li, N., Xiao, C., Yin, X., et al. (2013). Putative cobalt- and nickel-binding proteins and motifs in Streptococcus pneumoniae. Metallomics 5, 928-935. doi: 10.1039/c3mt00126a

Tai, S. S., Lee, C. J., and Winter, R. E. (1993). Hemin utilization is related to virulence of Streptococcus pneumoniae. Infect. Immun. 61, 5401-5405.

Tai, S. S., Wang, T. R., and Lee, C. J. (1997). Characterization of hemin binding activity of Streptococcus pneumoniae. Infect. Immun. 65, 1083-1087.

Talkington, D. F., Brown, B. G., Tharpe, J. A., Koenig, A., and Russell, H. (1996). Protection of mice against fatal pneumococcal challenge by immunization with pneumococcal surface adhesin A (PsaA). Microb. Pathog. 21, 17-22. doi: 10.1006/mpat.1996.0038

Tettelin, H., Nelson, K. E., Paulsen, I. T., Eisen, J. A., Read, T. D., Peterson, S., et al. (2001). Complete genome sequence of a virulent isolate of Streptococcus pneumoniae. Science 293, 498-506. doi: 10.1126/science.1061217

Throup, J. P., Koretke, K. K., Bryant, A. P., Ingraham, K. A., Chalker, A. F., Ge, Y., et al. (2000). A genomic analysis of two-component signal transduction in Streptococcus pneumoniae. Mol. Microbiol. 35, 566-576. doi: 10.1046/j.13652958.2000.01725.x

Trappetti, C., Potter, A. J., Paton, A. W., Oggioni, M. R., and Paton, J. C. (2011). LuxS mediates iron-dependent biofilm formation, competence, and fratricide in Streptococcus pneumoniae. Infect. Immun. 79, 4550-4558. doi: 10.1128/IAI.05644-11

Tseng, H. J., McEwan, A. G., Paton, J. C., and Jennings, M. P. (2002). Virulence of Streptococcus pneumoniae: PsaA mutants are hypersensitive to oxidative stress. Infect. Immun. 70, 1635-1639. doi: 10.1128/IAI.70.3.1635-1639.2002

Tsuruga, M., and Shikama, K. (1997). Biphasic nature in the autoxidation reaction of human oxyhemoglobin. Biochim. Biophys. Acta 1337, 96-104. doi: 10.1016/S0167-4838(96)00156-2

Ulijasz, A. T., Andes, D. R., Glasner, J. D., and Weisblum, B. (2004). Regulation of iron transport in Streptococcus pneumoniae by RitR, an orphan response regulator. J. Bacteriol. 186, 8123-8136. doi: 10.1128/JB.186.23.8123-8136.2004

van Opijnen, T., and Camilli, A. (2012). A fine scale phenotype-genotype virulence map of a bacterial pathogen. Genome Res. 22, 2541-2551. doi: $10.1101 /$ gr. 137430.112

Vidal, J. E., Howery, K. E., Ludewick, H. P., Nava, P., and Klugman, K. P. (2013). Quorum-sensing systems LuxS/autoinducer 2 and Com regulate Streptococcus pneumoniae biofilms in a bioreactor with living cultures of human respiratory cells. Infect. Immun. 81, 1341-1353. doi: 10.1128/IAI.01096-12

Vidal, J. E., Ludewick, H. P., Kunkel, R. M., Zahner, D., and Klugman, K. P. (2011). The LuxS-dependent quorum-sensing system regulates early biofilm formation by Streptococcus pneumoniae strain D39. Infect. Immun. 79, 4050-4060. doi: 10.1128/IAI.05186-11

Wang, Y., Zhu, S., Hodgkinson, V., Prohaska, J. R., Weisman, G. A., Gitlin, J. D., et al. (2012a). Maternofetal and neonatal copper requirements revealed by enterocyte-specific deletion of the Menkes disease protein. Am. J. Physiol. Gastrointest. Liver Physiol. 303, G1236-G1244. doi: 10.1152/ajpgi.00339.2012

Wang, Y., Zhu, S., Weisman, G. A., Gitlin, J. D., and Petris, M. J. (2012b). Conditional knockout of the Menkes disease copper transporter demonstrates its critical role in embryogenesis. PLOS ONE 7:e43039. doi: 10.1371/journal.pone.0043039

Wardlaw, T., Johansson, E., and Hodge, M. (2006). Pneumonia the Forgotten Killer of Children. The United Nations Children's Fund (UNICEF)/World Health Organization (WHO). Available online at: http://www.unicef.org/publications/index_35626.html

Weinberg, E. D. (2009). Iron availability and infection. Biochim. Biophys. Acta 1790, 600-605. doi: 10.1016/j.bbagen.2008.07.002

Whalan, R. H., Funnell, S. G., Bowler, L. D., Hudson, M. J., Robinson, A., and Dowson, C. G. (2005). PiuA and PiaA, iron uptake lipoproteins of Streptococcus pneumoniae, elicit serotype independent antibody responses following human pneumococcal septicaemia. FEMS Immunol. Med. Microbiol. 43, 73-80. doi: 10.1016/j.femsim.2004.07.010

Whalan, R. H., Funnell, S. G., Bowler, L. D., Hudson, M. J., Robinson, A., and Dowson, C. G. (2006). Distribution and genetic diversity of the ABC transporter lipoproteins PiuA and PiaA within Streptococcus pneumoniae and related streptococci. J. Bacteriol. 188, 1031-1038. doi: 10.1128/JB.188.3. 1031-1038.2006

White, C., Lee, J., Kambe, T., Fritsche, K., and Petris, M. J. (2009). A role for the ATP7A copper-transporting ATPase in macrophage bactericidal activity. J. Biol. Chem. 284, 33949-33956. doi: 10.1074/jbc.M109.070201 
Yesilkaya, H., Kadioglu, A., Gingles, N., Alexander, J. E., Mitchell, T. J., and Andrew, P. W. (2000). Role of manganese-containing superoxide dismutase in oxidative stress and virulence of Streptococcus pneumoniae. Infect. Immun. 68, 2819-2826. doi: 10.1128/IAI.68.5. 2819-2826.2000

Zapotoczna, M., Jevnikar, Z., Miajlovic, H., Kos, J., and Foster, T. J. (2013). Iron-regulated surface determinant B (IsdB) promotes Staphylococcus aureus adherence to and internalization by non-phagocytic human cells. Cell. Microbiol. 15, 1026-1041. doi: 10.1111/cmi.12097

Conflict of Interest Statement: The authors declare that the research was conducted in the absence of any commercial or financial relationships that could be construed as a potential conflict of interest.
Received: 14 August 2013; accepted: 19 November 2013; published online: 04 December 2013.

Citation: Honsa ES, Johnson MDL and Rosch JW (2013) The roles of transition metals in the physiology and pathogenesis of Streptococcus pneumoniae. Front. Cell. Infect. Microbiol. 3:92. doi: 10.3389/fcimb.2013.00092

This article was submitted to the journal Frontiers in Cellular and Infection Microbiology.

Copyright (C) 2013 Honsa, Johnson and Rosch. This is an open-access article distributed under the terms of the Creative Commons Attribution License (CC BY). The use, distribution or reproduction in other forums is permitted, provided the original author(s) or licensor are credited and that the original publication in this journal is cited, in accordance with accepted academic practice. No use, distribution or reproduction is permitted which does not comply with these terms. 